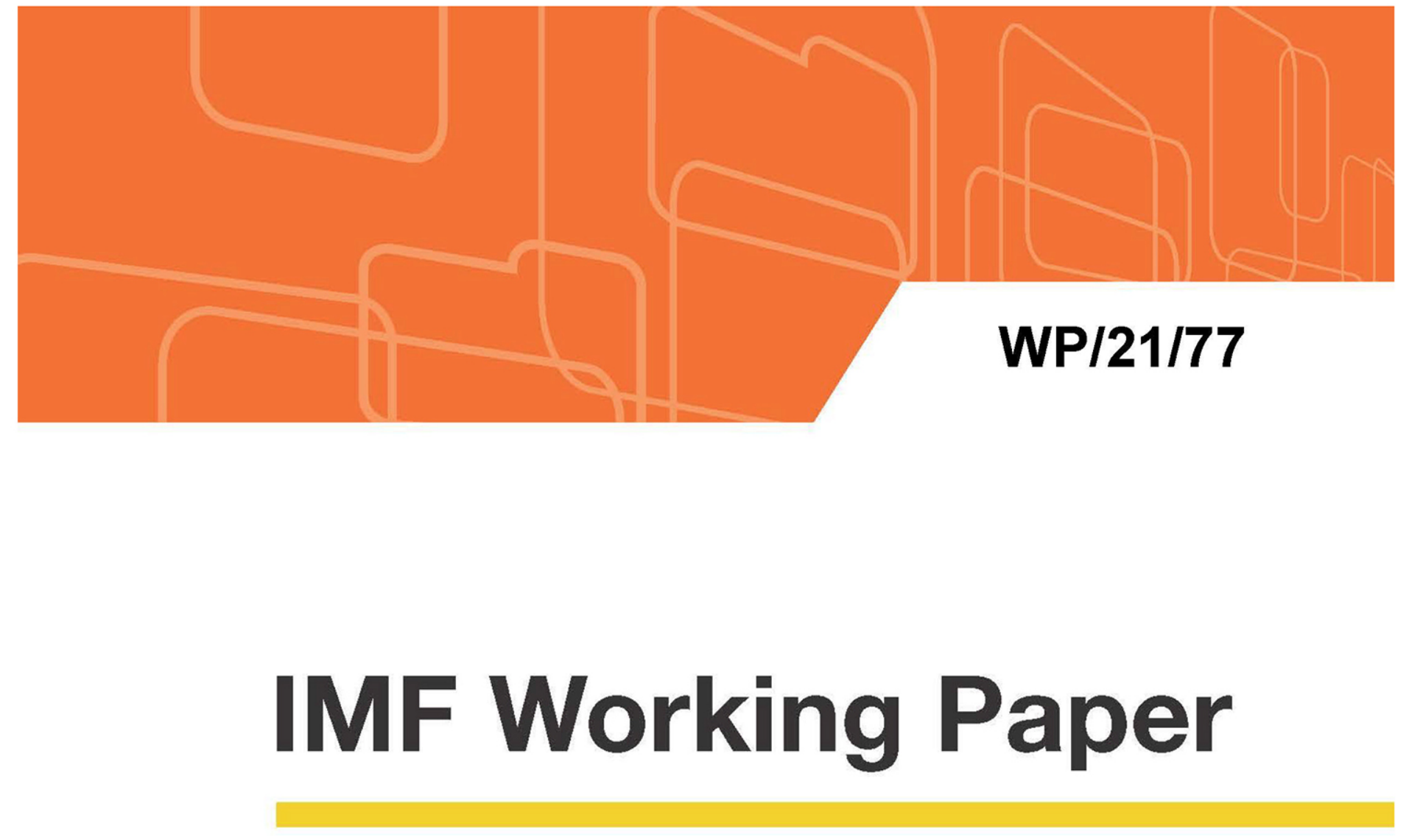

\title{
Fiscal Policy Challenges for Latin America During the Next Stages of the Pandemic: The Need for a Fiscal Pact
}

by Mauricio Cardenas, Luca Antonio Ricci, Jorge Roldos, and Alejandro Werner

IMF Working Papers describe research in progress by the author(s) and are published to elicit comments and to encourage debate. The views expressed in IMF Working Papers are those of the author(s) and do not necessarily represent the views of the IMF, its Executive Board, or IMF management.

$$
\text { I N T E R N A T I O N A L M O N E T A R Y F U N D }
$$




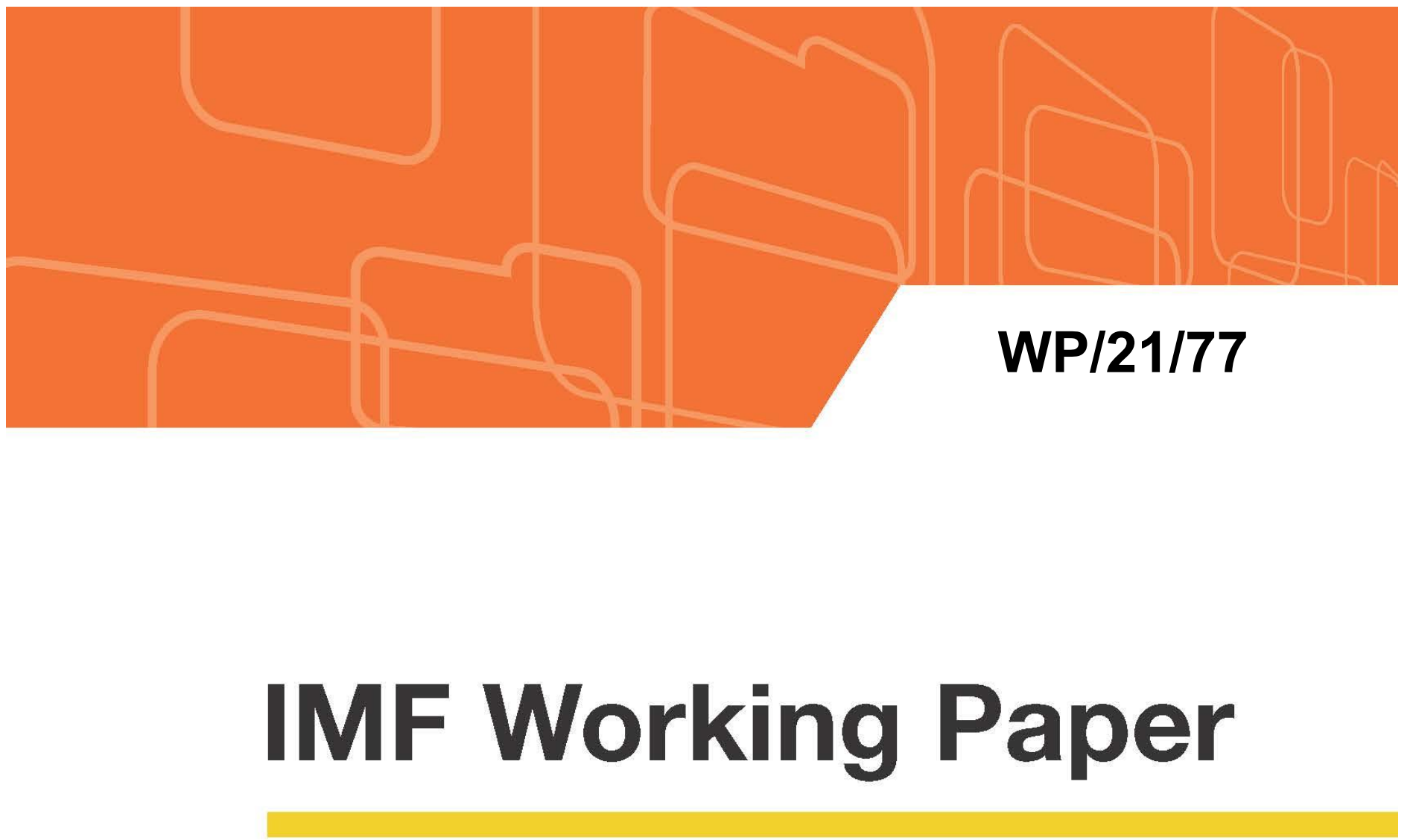

\section{Fiscal Policy Challenges for Latin America During the Next Stages of the Pandemic: The Need for a Fiscal Pact}

by Mauricio Cardenas, Luca Antonio Ricci, Jorge Roldos, and Alejandro Werner

IMF Working Papers describe research in progress by the author(s) and are published to elicit comments and to encourage debate. The views expressed in IMF Working Papers are those of the author(s) and do not necessarily represent the views of the IMF, its Executive Board, or IMF management.

$$
\text { I N TER N A T | O N A L M O N E T A R Y F U N D }
$$




\title{
IMF Working Paper
}

Western Hemisphere Department

\section{Fiscal Policy Challenges for Latin America during the Next Stages of the Pandemic: The Need for a Fiscal Pact}

\author{
Prepared by Mauricio Cardenas, Luca Antonio Ricci, Jorge Roldos, and Alejandro Werner
}

Authorized for distribution by Alejandro Werner

March 2021

IMF Working Papers describe research in progress by the author(s) and are published to elicit comments and to encourage debate. The views expressed in IMF Working Papers are those of the author(s) and do not necessarily represent the views of the IMF, its Executive Board, or IMF management.

\begin{abstract}
The fiscal policy response to the COVID-19 shock in most LAC countries was much larger than during the GFC, suggesting fiscal space was not as tight as expected. We argue that it is feasible and desirable, though not without risks, to embark in a more gradual consolidation path than currently envisaged by several countries in the region. Avoiding an early withdrawal of support in 2021 and 2022 is important given that countries are still facing high rates of contagion and deaths, vaccination will take place very slowly, the economic recovery is partial, uncertain and not strong enough to help those most affected by the twin public health and economic crisis. At the center of this discussion is our conviction that fiscal space is not set in stone and it is endogenous to the medium-term targets and commitments undertaken by governments and congresses throughout the region. Also, revisions to fiscal responsibility frameworks should help anchor fiscal sustainability, as well as improve their effectiveness and flexibility. In this context, low-for-long interest rates and easy market access is generating a situation that, in spite of higher debt levels, interest cost on public debt will remain contained in the foreseeable future. Especially if, as argued in this paper, a more gradual fiscal consolidation path is accompanied with stronger commitments and institutional frameworks that ensure debt is put on a credible downward trajectory once the pandemic is under control. Catalyzing these changes, as well as initiating the debate to design other fiscal reforms to strengthen social protection and increase the progressivity of public finances, would require a broad social consensus and political cohesion around several crucial dimensions of public finances: a fiscal pact. On the other hand, if this agenda is neglected the continuation of low growth, social discontent, and political polarization could drive Latin America towards a very dangerous path of institutional and economic decay.
\end{abstract}

JEL Classification Numbers: E43, E62, H63

Keywords: fiscal policy, fiscal space, public debt 


\section{Introduction}

Latin America has been the hardest hit region in the world by COVID-19, both in terms of lives and livelihoods. With only 8 percent of the world population, as of January 2021 the region has 18 percent of the world's COVID-19 cases and 28 percent of deaths associated with the virus. As a result, in 2020 the region experienced its deepest economic contraction in almost a century with severe implications on poverty and income distribution. Although fiscal space was limited in the region, many countries put together significant fiscal support packages to help households and firms, and to strengthen the health system. Announced discretionary above-the-line fiscal measures added up to around 4.5 percent of GDP, and to around 8 percent including below-the-line and off-budget measures. Additionally, government revenues declined by 2.3 percent of GDP due to the pandemic, leading to a primary balance deterioration of around 6 percent of GDP. As a result, public debt in the region increased from 64 in 2019 to 72 percent of GDP in 2020 and is expected to remain around 71 percent of GDP until at least 2025.

Looking forward, fiscal policy faces multiple challenges related both to the optimal response to the COVID19 shock and to those issues that the region was facing before the pandemic, which in some countries contributed to the social protests that took place during 2019. Many analysts have highlighted the role played by insufficient social safety nets and low quality of public services as important factors behind these social movements. In this paper we analyze these challenges and suggest that a broad fiscal pact is needed in many countries in the region. This fiscal pact will have to tackle the necessity to continue to support households and firms during the next stages of the pandemic, while ensuring favorable market access conditions by guaranteeing a strong medium-term fiscal anchor and credibly communicating a clear path on how to reach fiscal targets once the pandemic fades away and the economy goes back to potential. Secondly, this fiscal discussion has to tackle the medium-term challenges of broadening the social safety net and improving the quality of public services, while also guaranteeing the medium-term sustainability of public finances and the build-up of adequate buffers to cope with possible future shocks. As we argue in the paper this task will need to redesign the public health, education and pension frameworks, while rationalizing other expenditure as well as improving the reach, progressivity, and effectiveness of the tax systems.

A complementary fundamental challenge will be posed by the necessity to implement an important redesign of the fiscal responsibility frameworks. Although the region has been a leader in the establishment and in the design of these frameworks, the decade that followed the GFC evidenced important shortcomings in these systems. On the benefits side, the different fiscal responsibility frameworks used in the region allowed authorities to act aggressively during the most severe negative shocks in the last 15 years, the GFC and COVID-19. However, the frameworks have been relatively weak in bringing fiscal balances back to normal levels in the medium term, creating an important upward bias in the path of public debt that led to a worsening trend in sovereign credit quality throughout the region. The region has been fortunate that these developments coincided with the decline of international interest rates and, therefore, the impact of the increases in debt on the interest costs of public debt has been mild.

Tackling the multiple elements of this fiscal pact presents both technical and political challenges, which requires a two-stage process. On the one hand, dealing with the next stage of the pandemic response in a way that supports the recovery without triggering sustainability concerns is an urgent matter. On the other hand, redesigning the social safety net and the tax and expenditure system is a medium-term structural issue that requires an in-depth social dialogue on the role of the state and how to finance it in a sustainable fashion. We believe these two sets of changes would be best implemented in a two-stage process. The first, and urgent, stage should cover the optimal path for fiscal policy in a way that avoids an early and excessive withdrawal of fiscal support during the pandemic while at the same time reassuring financial markets of the medium-term sustainability of public finances. At the center of this discussion is our conviction that fiscal space is not set in stone and it is endogenous to the medium-term targets and commitments undertaken by governments and congresses throughout the region. To achieve this, the fiscal targets that are decided should be accompanied with measures that increase public sector net revenues once the economy and employment levels are clearly on the mend and close to potential. Also, revisions to fiscal responsibility frameworks should be helpful to 
anchor fiscal sustainability perceptions, as well as to improve their effectiveness and flexibility. This first stage is urgent and should establish the fiscal principles that will sustain the support for households and firms in the next stages of the pandemic as well as supporting the post pandemic economic recovery, together with the strengthening of the fiscal rules that will guide the process of fiscal consolidation in the future and some of the measures that will be implemented to accomplish this. Low-for-long international interest rates and easy market access is generating a situation that, in spite of higher debt levels, interest cost on public debt will remain contained in the foreseeable future. Also, to complement this strategy, financial arrangements with the IFI's could limit any negative effect on markets by reducing the issuance of sovereign market debt and by increasing the credibility of the medium-term (MT) fiscal commitments.

The second stage should start with a social consultation on how to broaden the social safety net and how to finance it, to assess society's preferences regarding the tax and expenditure implications behind these very consequential tradeoffs. This public dialogue should serve as a basis into the legislative process that should take place in the next couple of years to revise pensions, health, and educational systems as well as reforming tax frameworks to support it. The fiscal system in Latin America is not progressive enough given regional development levels and societies preferences as reflected in recent social movements and political developments. Some countries in the region need to improve the coverage and targeting of their spending while others need to increase tax revenues and expand their safety nets.

This agenda is definitively challenging and risky but if it is neglected the continuation of low growth, social discontent, and political polarization might drive Latin America towards a very dangerous path of institutional and economic decay. Catalyzing such changes would require a broad social consensus and political cohesion around several crucial dimensions of public finances: a fiscal pact.

The next section describes the 2020 fiscal response and its impact on economic and social outcomes. We then focus on the initial conditions before the COVID-19 shock, compared to the GFC, and conclude that while fiscal space appeared to be less this time around it was indeed larger than initially expected. We then move to compare the region's fiscal policy in 2021 and beyond with that of other EMDC and conclude that with the right medium-term commitments and institutions there is room to continue providing fiscal support in the near term. Finally, we discuss some expenditure and revenue measures that could be implemented in the two stages, as well as how institutional fiscal frameworks could be strengthened to ensure that a more gradual consolidation strategy addresses sustainability concerns.

\section{The Fiscal Policy Response to COVID-19}

Most countries in the region responded to the COVID-19 shock with large fiscal and quasi-fiscal support packages. These packages included different type of measures, such as increases in expenditures, decreases in taxes, tax deferrals and loan guarantees aimed at mitigating the socio-economic impact of the shock. The announced fiscal support amounted to around 8 percent of the region's GDP and included above-the-line and below-the-line and contingent measures (such as credit guarantees), with the above-the-line fiscal announcements averaging 4.5 percent of GDP (Figure 1). 
Figure 1. Fiscal Developments

\section{Discretionary Fiscal Measures ${ }^{1}$} (Percent of GDP)

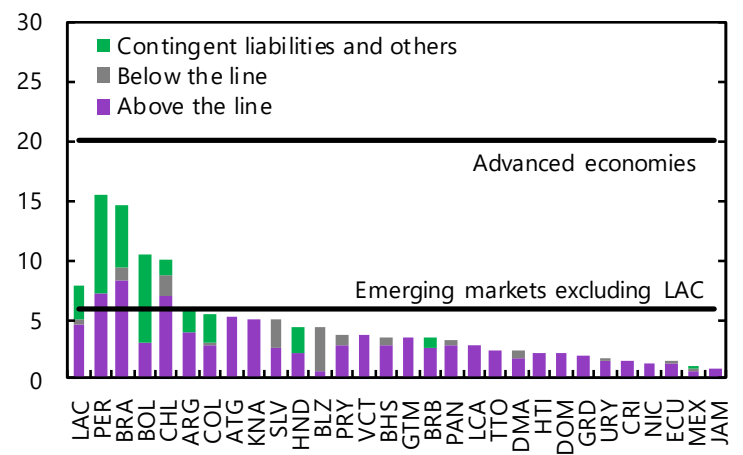

2. Above-the-Line Discretionary Fiscal Measures ${ }^{2}$ (Percent of GDP)

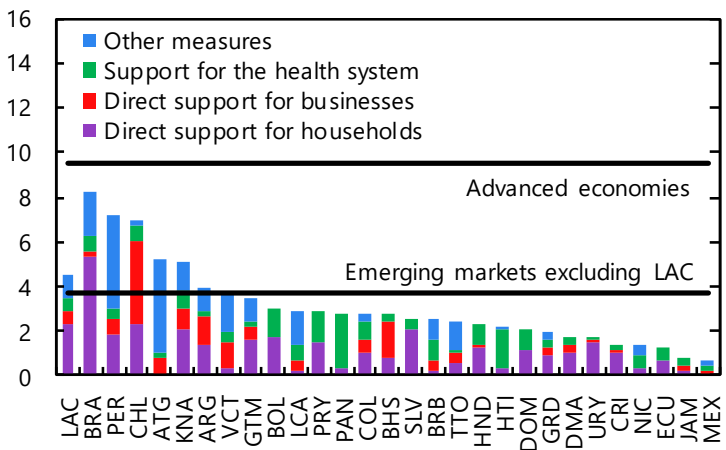

Sources: IMF, Fiscal Monitor Database of Country Fiscal Measures in Response to the COVID-19 Pandemic (https://www.imf.org/en/Topics/imf-and-covid19/FiscalPolicies-Database-in-Response-to-COVID-19); IMF, October 2020 Regional Economic Outlook: Western Hemisphere; IMF, World Economic Outlook database; national authorities; and IMF staff calculations.

Note: Advanced economies, emerging market economies excluding LAC, and LAC aggregates are fiscal year US dollar nominal GDP-weighted averages. LAC includes countries shown in the chart. Announced measures changed over the course of the year and for some countries include spending in the following years. Does not include tax deferrals and anticipation of benefits, which typically have small effects on an annual basis.

${ }^{1}$ For most countries, the loan guarantees include the total potential amount of loans covered by the guarantees; for Chile and Colombia, the amount corresponds to the capital committed for such purposes.

${ }^{2}$ In Peru, other measures include mostly capital spending; in Brazil, they mostly include support to local governments.

The size of announced packages correlates to some extent with perceived measures of fiscal space. As the Figure 2 below suggest, there is some negative correlation between the size of the discretionary fiscal measures and the ratios of debt-to-GDP and spreads. Still, it is noteworthy that Brazil and Bolivia appear to have succeeded in announcing packages of similar sizes to Peru and Chile, respectively, with much higher levels of debt and spreads (and lower credit ratings), and that Mexico, a country that had some fiscal space, decided to implement one of the smallest packages in the region.

Figure 2. Discretionary Fiscal Measures, Gross Debt, and EMBIG Spreads
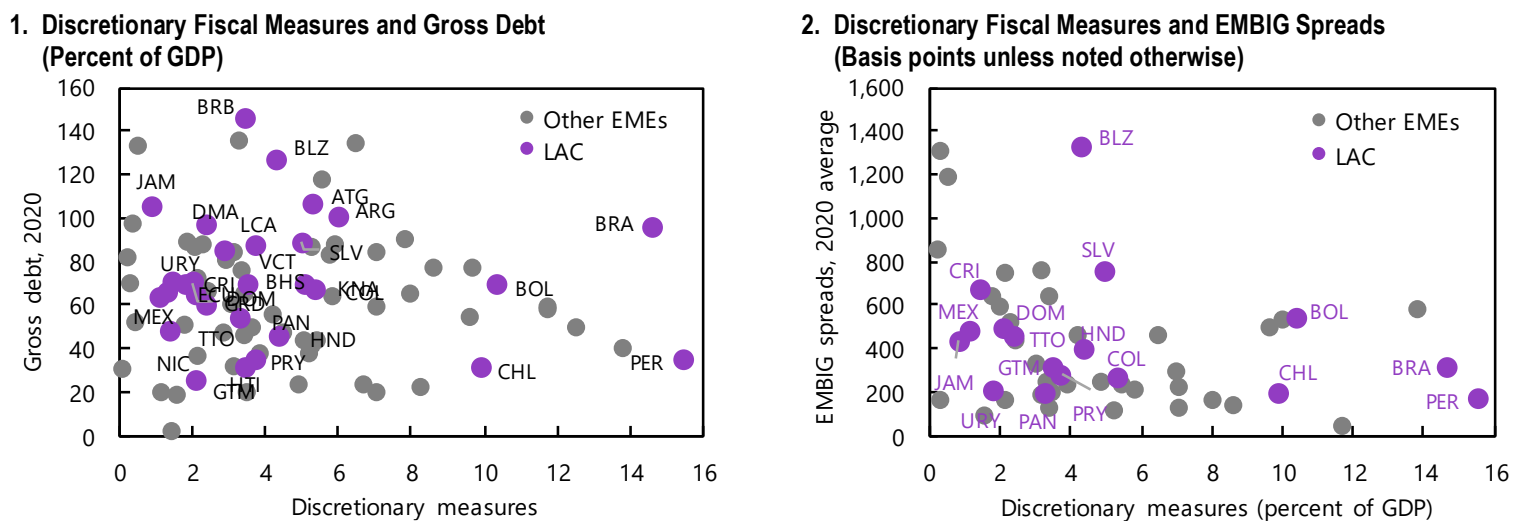

Sources: IMF, Fiscal Monitor Database of Country Fiscal Measures in Response to the COVID-19 Pandemic (https://www.imf.org/en/Topics/imf-and-covid19/FiscalPolicies-Database-in-Response-to-COVID-19); IMF, World Economic Outlook database; national authorities; and IMF staff calculations.

Note: Does not include tax deferrals and anticipation of benefits, which typically have small effects on an annual basis. For most countries, the loan guarantees include the total potential amount of loans covered by the guarantees; for Chile and Colombia, the amount corresponds to the capital committed for such purposes.

The impact of these fiscal responses has to be analyzed from at least three dimensions: first, how much of the announced program has been implemented and how timely implementation has been; second, the impact on employment and poverty; and third, the impact on overall GDP and activity.

Some countries initially faced difficulties in rolling out the announced packages, and measures varied in their timing and implementation over the year. A simple way to assess the timing and impact of the implemented measures is to compare the observed evolution of primary government spending and that of quarterly GDP, as done in the next Figure 3. The comparison suggests that Brazil and Colombia were able to implement a large 
share of their announced measures in a timely manner, contributing to the rebound in Q3 GDP, ${ }^{1}$ while Chile and Peru delayed somewhat their support until the third quarter of 2020. Moreover, the last two countries faced constraints in the implementation of pre-existing capex plans, resulting in declines in public investment that compensated to some extent the positive impulse on activity from current expenditures. Both countries also had announced measures that spilled over to 2021 and this contributed to the gaps between announced and implemented measures. Implementation of below the line measures has also been uneven, but Peru stands out with strong implementation and even an expansion of the Reactiva Peru program of credit guarantees. ${ }^{2}$

Figure 3. Real GDP and Primary Expenditures

(Line series: Year-over-year percentage change; Bar series: Expenditures in percent of GDP; right scale)

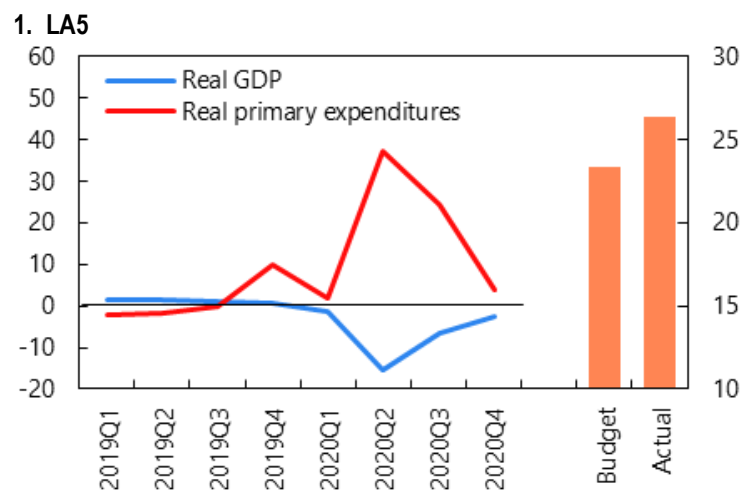

3. Chile
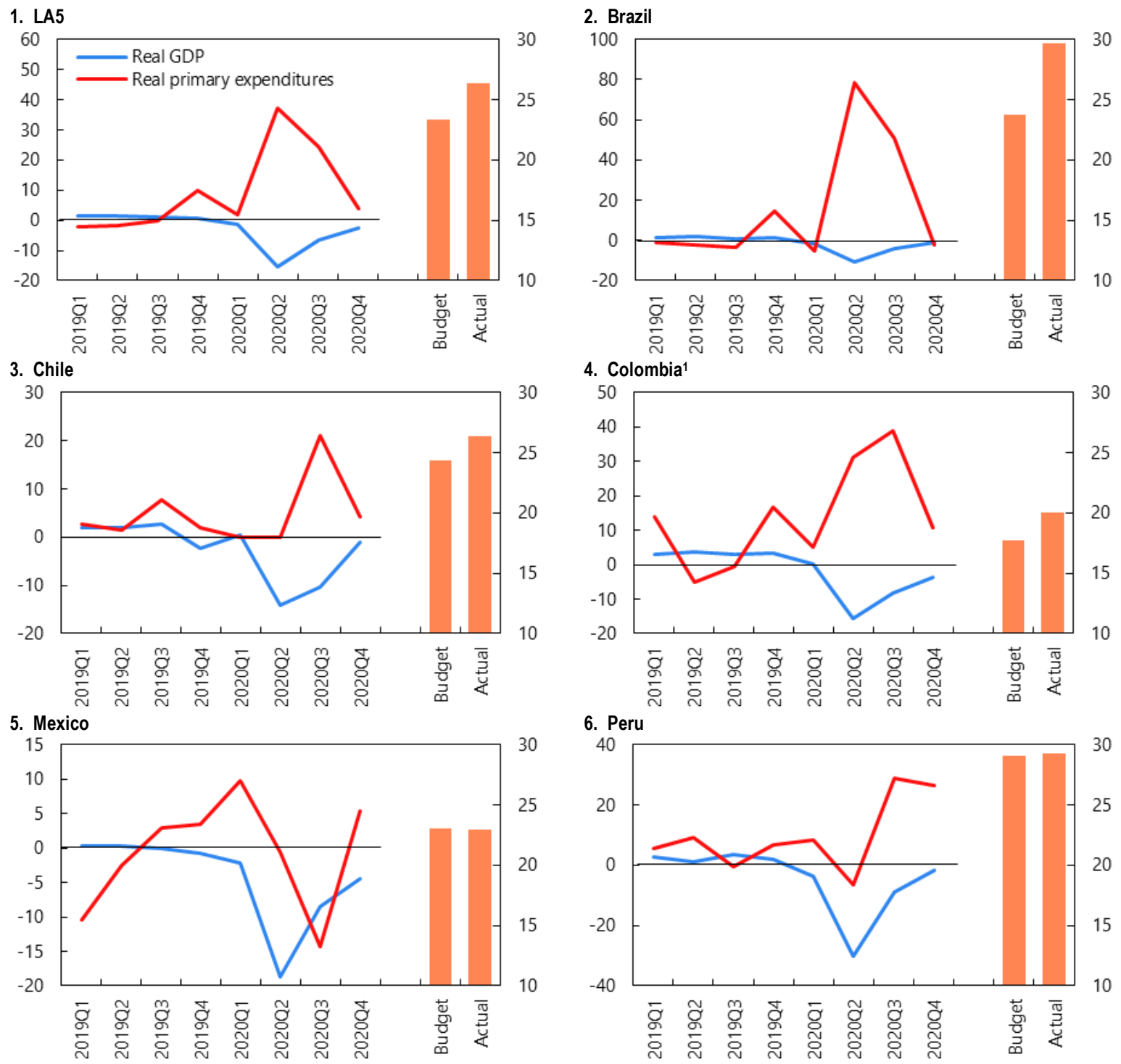

Sources: Haver Analytics; IMF, World Economic Outlook database; national authorities; and authors' calculations.

Note: LA5 is the weighted average of Brazil, Chile, Colombia, Mexico, and Peru. "Budget" refers to the pre-COVID (budget) primary expenditures for 2020. "Actual" refers to the 2020 actual primary expenditures.

${ }^{1}$ Colombia's primary expenditure for $2020 \mathrm{Q} 4$ is a preliminary estimate.

The focus of the fiscal measures was on saving lives and livelihoods. The former was associated to expanded spending on health, and countries added around 0.7 percent of GDP on this issue-with large variance, for

${ }^{1}$ Of course, the rebound is also associated with the removal of lockdowns and other factors.

${ }^{2}$ On Peru's Reactiva Peru program, see EIU (2020). 
instance, 0.2 percent of GDP in Mexico versus 1.1 percent of GDP in Brazil. The bulk of the above-the-line support was on protecting formal employment and increasing transfers to informal workers and other vulnerable segments of the population, as well as providing liquidity support to SME. The job protection measures included programs such as the employment retention plan in Brazil, that covered around 10 million jobs at a cost of just 0.4 percent of GDP, and delivered the best relative performance in terms of formal employment of the largest economies in the region (see Figure 4).

\section{Figure 4. Formal and Informal Employment Index}

\section{(Index: January $2020=100$ )}

\section{Brazil}

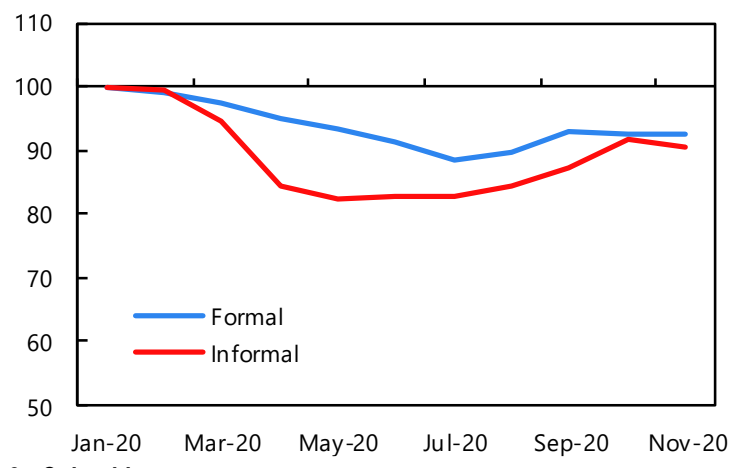

3. Colombia

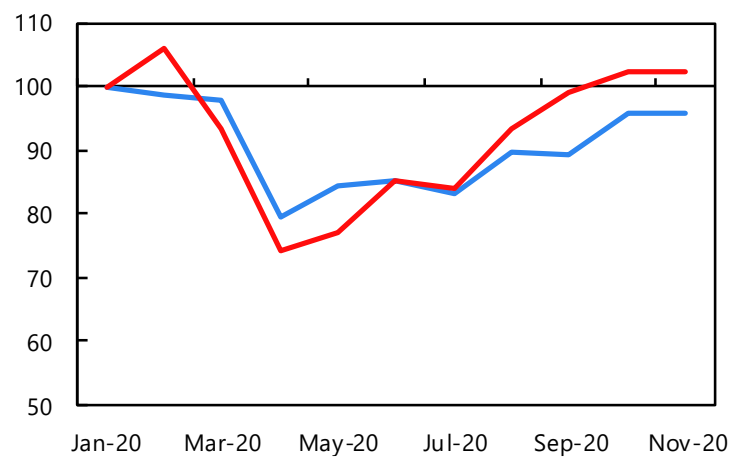

\section{Chile}

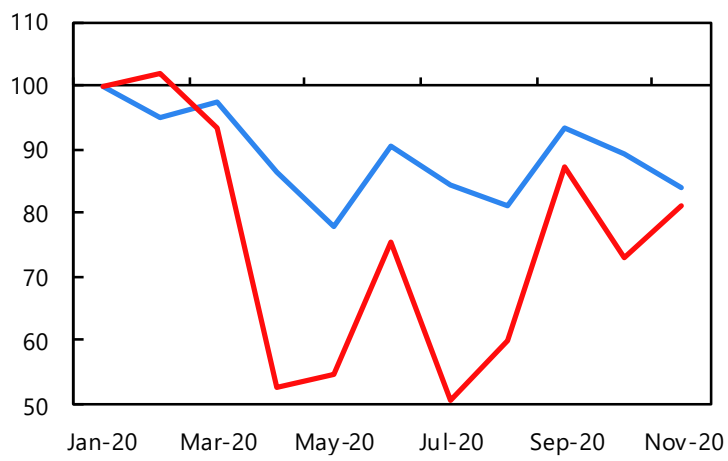

4. Mexico

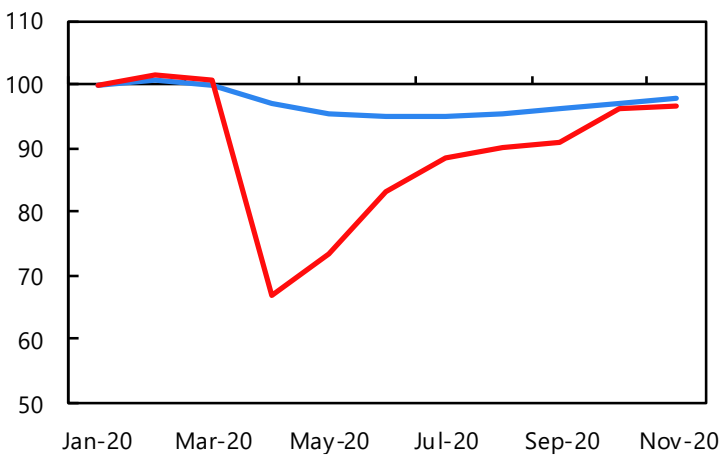

Sources: Haver Analytics; national authorities; and authors' calculations.

Note: Data for Brazil and Chile are transformed to reflect month-on-month employment changes. For Colombia, the values from March to June are imputed.

The packages also provided a buffer to increases in poverty. Early estimates (Lustig et al, 2020) suggested that from an expected increase in poverty of around 30 million in Argentina, Brazil, Colombia and Mexico, in the absence of compensatory policies, the implementation of support measures would have contained the increase to around 15-17 million (see Table 1 below). In the case of Brazil, the Emergency Assistance program has actually managed to reduce poverty to below pre-COVID-19 levels and also improve the Gini coefficient.

\section{Table 1. Estimated Impact of COVID-19 on Poverty}

(Millions)

\begin{tabular}{|c|c|c|c|c|c|c|c|c|c|c|}
\hline \multirow[b]{3}{*}{ Source } & \multirow{3}{*}{$\begin{array}{c}\text { Change in Extreme Poverty } \\
\text { Headcount (below US } \$ 1.90 \\
\text { per capita per day) } \\
\text { LAC }\end{array}$} & \multicolumn{9}{|c|}{ Change in Poverty Headcount (below US $\$ 5.50$ per capita per day) } \\
\hline & & \multirow[b]{2}{*}{ LAC } & \multicolumn{2}{|c|}{ Argentina } & \multicolumn{2}{|c|}{ Brazil } & \multicolumn{2}{|c|}{ Colombia } & \multicolumn{2}{|c|}{ Mexico } \\
\hline & & & COVID-19 & $\begin{array}{c}\text { COVID-19+ } \\
\text { Assistance }\end{array}$ & COVID-19 & $\begin{array}{c}\text { COVID-19+ } \\
\text { Assistance }\end{array}$ & COVID-19 & $\begin{array}{c}\text { COVID-19+ } \\
\text { Assistance }\end{array}$ & COVID-19 & $\begin{array}{c}\text { COVID-19+ } \\
\text { Assistance }\end{array}$ \\
\hline $\begin{array}{l}\text { October } 2020 \text { Fiscal Monitor } \\
\text { World Bank (June 2020) } \\
\text { ECLAC (July 2020) }\end{array}$ & 14.7 & $\begin{array}{c}18-35 \\
44\end{array}$ & 1.48 & & 6.86 & & 2.66 & & 9.21 & \\
\hline Lustig and others (2020) & & & $1.4-2.0$ & $0.5-1.7$ & $9.3-13.9$ & $(0.4)-5.3$ & $2.5-2.9$ & $2.2-2.7$ & $10.1-11.2$ & n.a. \\
\hline
\end{tabular}

Sources: Haver Analytics; national authorities; and IMF staff calculations.

Note: Data for Brazil and Chile are transformed to reflect month-on-month employment changes. For Colombia, the values from March to June are imputed. 
Although is difficult to isolate the direct impact of these measures, they seem to be having the desired impact of supporting economic activity and providing income to the most vulnerable in 2020. ${ }^{3}$ The sharp increase in transfers in Brazil, associated with the Emergency Assistance program, is likely to have contributed to cushioning the fall in Q2 GDP — as well as the above-mentioned decline in poverty and inequality. In Chile and Peru, the increase in government spending in Q3, combined with the large drawdowns from private pension funds (as a result of changes in regulations), have likely supported the recovery in that quarter (see Figure 5). Further implementation of announced packages in Q4, combined with momentum in activity following better-than-expected Q3 GDP outcomes, contributed to a stronger-than-expected performance for the year a whole. It is unclear, though, whether these support measures have forestalled a spike in bankruptcies and unemployment, or if they have just delayed the day of reckoning.

Simulations presented in the October 2020 WHD-Regional Economic Outlook suggest that the measures implemented would have buffered the output decline due to the pandemic and associated containment measures by around 3 percent. ${ }^{4}$ Although a structural model has more precise and direct impacts of the implemented measures, it lacks the sectoral richness to accommodate the differential impact of the COVID19 shock. This suggests the 3 percent would be an upper bound to the cushioning effect of the measures. Adding the impact of below the line measures, this support would have been between 4 and 5 percent of GDP (see WHD-REO, Fiscal Chapter).

In sum, the discretionary fiscal response measures of LAC countries, coupled with the drop in revenues associated with the sharp recession, increased deficits and debt levels in 2020. The overall fiscal balance for LAC is expected to deteriorate by around 6 percentage points of GDP and the debt-to-GDP ratio to rise by around 8 percentage points (Figure 6). Some countries also resorted to the drawdown of existing buffers to finance the needed fiscal support, and regulatory measures to allow withdrawals from pension funds have contributed to support activity and incomes.

${ }^{3}$ Behavioral changes (fear of contagion) and containment measure are also key determinants of activity during this period (see REO, 2020, Chapter on pandemic).

${ }^{4}$ These are simulations from a structural model that, although calibrated to features of the actual LAC economies and using multipliers in line with empirical estimates, may not correspond with actual outcomes. 
Figure 5. Contributions to Real GDP Growth (Percent)

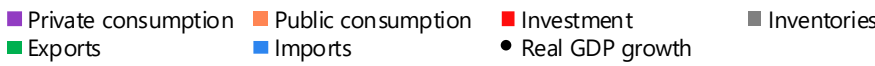

1. LA5

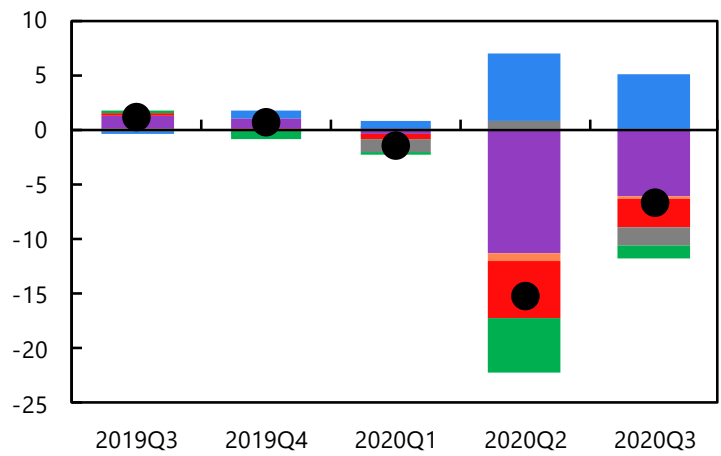

3. Chile

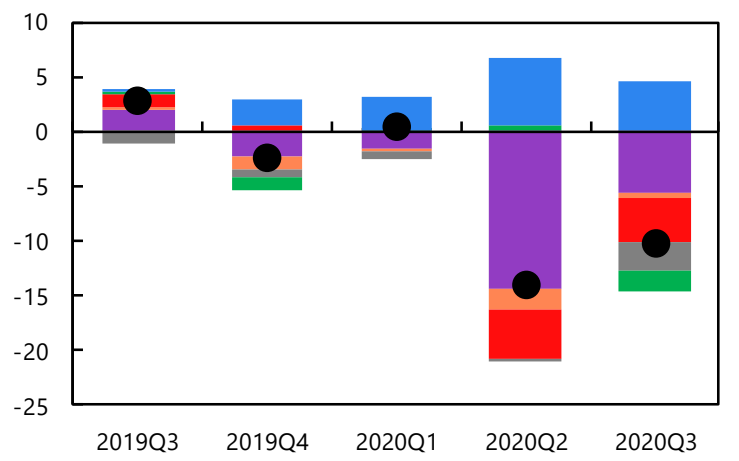

5. Mexico

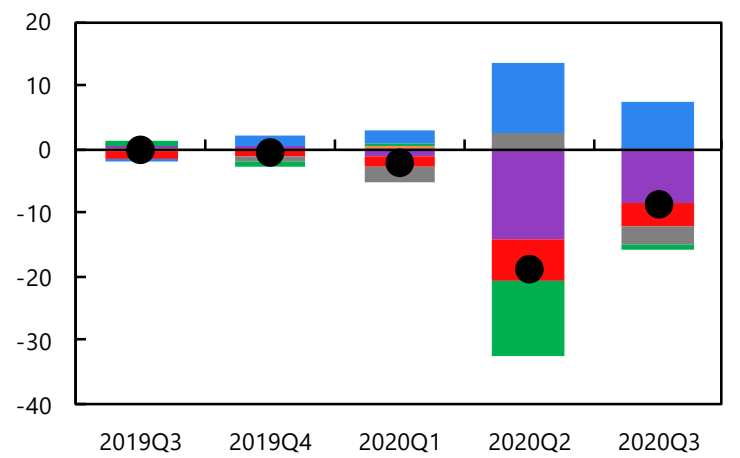

2. Brazil

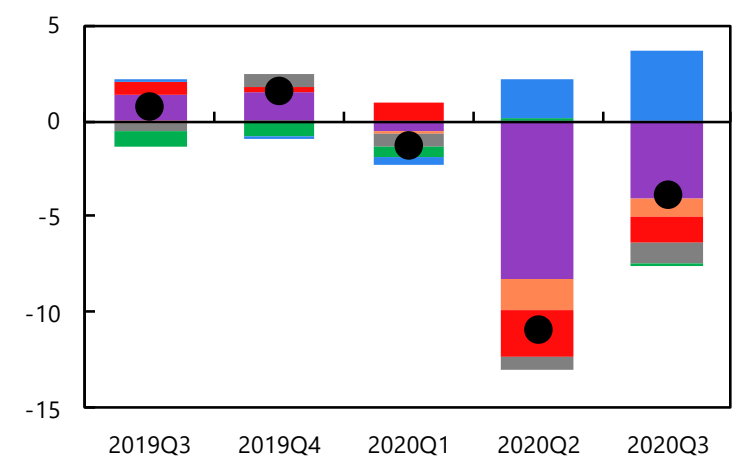

4. Colombia

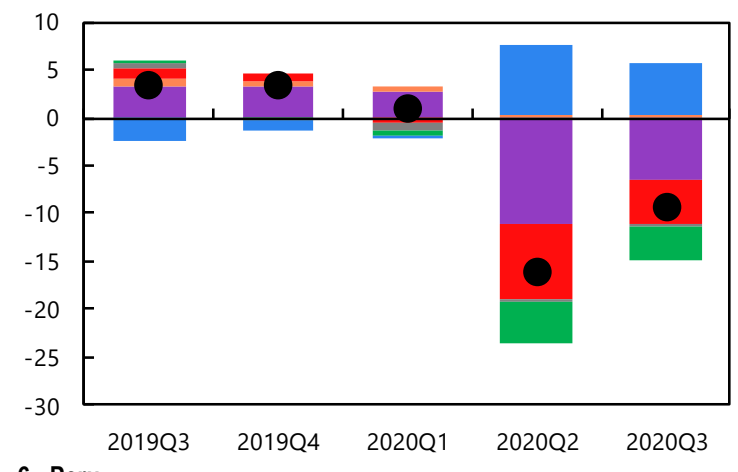

6. Peru

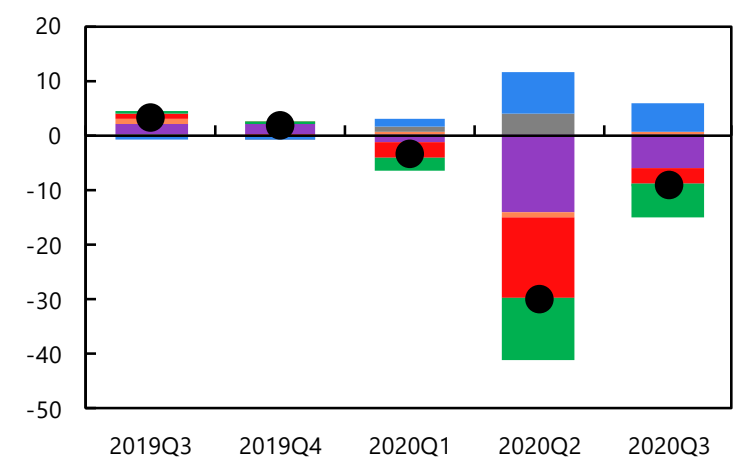

Sources: Haver Analytics; IMF, World Economic Outlook database; national authorities; and IMF staff calculations.

Note: LA5 is purchasing-power-parity GDP-weighted average of Brazil, Chile, Colombia, Mexico, and Peru. Inventories include statistical discrepancies. 
Figure 6. Fiscal Balance, Revenue, and Debt

1. Change in Fiscal Balance and Revenue, 2020 (Relative to 2019; percentage points of GDP)

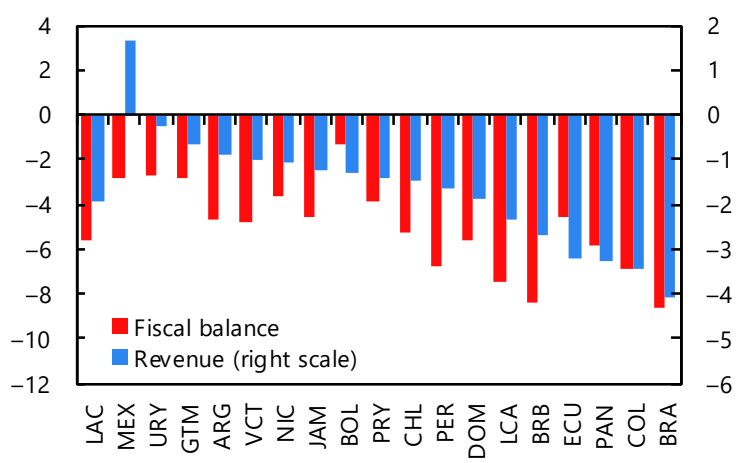

2. Drivers of Change in Public Debt, $2020^{1}$ (Percent of GDP)

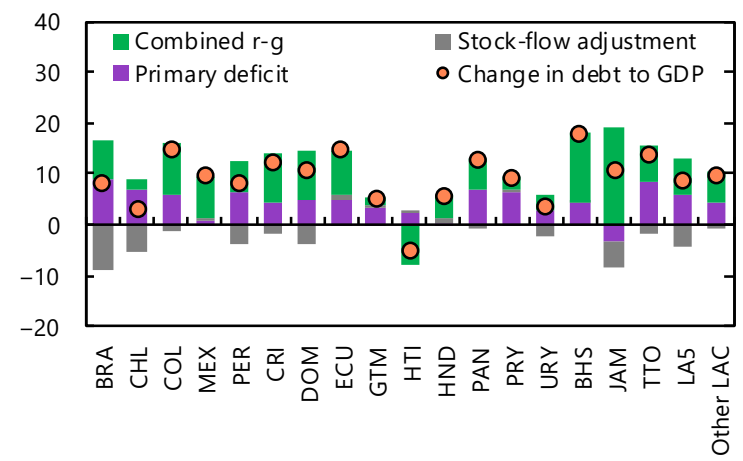

Sources: IMF, World Economic Outlook database; and authors' calculations.

Note: Aggregates are fiscal year US dollar nominal GDP-weighted averages. LA5 = Brazil, Chile, Colombia, Mexico, Peru.

${ }^{1}$ Real interest rate-growth differential, adjusted for exchange rate changes. Stock-flow adjustments are a residual category that typically captures one-off factors. For example, in the case of Brazil, they capture in part the use of cash reserves to meet financing needs, which partially reduces the need for new debt issuance. Other LAC includes the countries shown in the chart except for LA5.

\section{Initial Conditions: Fiscal Space in the GFC versus COVID-19 and the 2020 Response}

Fiscal space is a multi-dimensional concept that cannot be summarized in a few indicators but some of them suggest that the region faced the COVID-19 shock with less fiscal space than when confronted with the Global Financial Crisis (GFC) - though not as constrained as casual observation of debt-to-GDP ratios might suggest. In particular, countries in the region had higher deficits and debt levels in the wake of the COVID-19 shock, but international market conditions were more favorable this time around. In this respect, the secular decline in global and domestic interest rates, combined with the tricky and uncertain comparison of stocks and flows, raises the importance of interest payments as part of the discussion of budgetary and fiscal space. Moreover, the large monetary impulse undertaken by the advanced economies' (AE's) monetary authorities allowed emerging markets' (EM's) to be more aggressive in their macro policies response. This section focuses on initial conditions and backward-looking aspects of this question, while the next one moves to a more forward-looking discussion.

The region confronted the COVID-19 shock with higher levels of debt on average than before the GFC, but the currency composition of the debt was roughly the same in the wake of both episodes (Figure 7). Regional averages for total debt over GDP were around 20 percent higher before the COVID-19 shock than before the GFC, following even larger increases in Brazil, Costa Rica, Colombia, Ecuador, and Mexico. The share of foreign currency debt was slightly below 20 percent of total debt for the region in both episodes, though the average masks large reductions in Brazil, Chile, and Peru, and increases in Colombia and Mexico. Most countries had lengthened the average maturity of debt by 2019, but this was reversed in Brazil, Colombia, and Mexico-while interest paid increased for most economies but came down on average due to the important reduction experienced in Brazil. 
Figure 7. Debt Indicators before the Global Financial Crisis and COVID-19

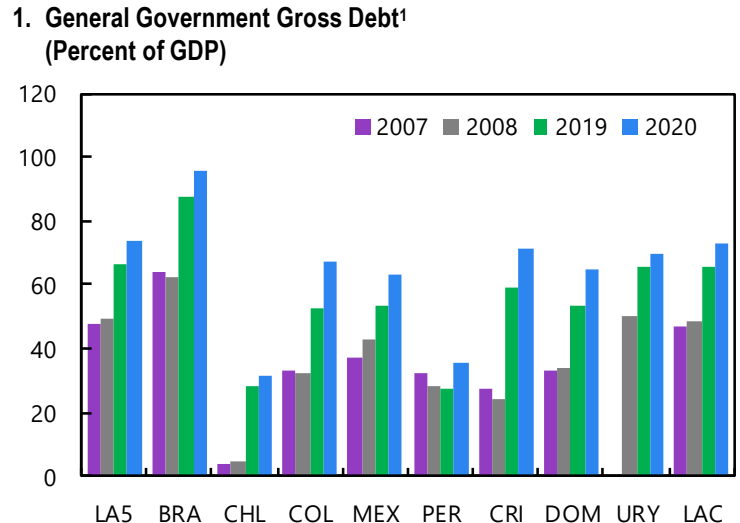

3. Average Maturity of Debt ${ }^{2}$

(Years)

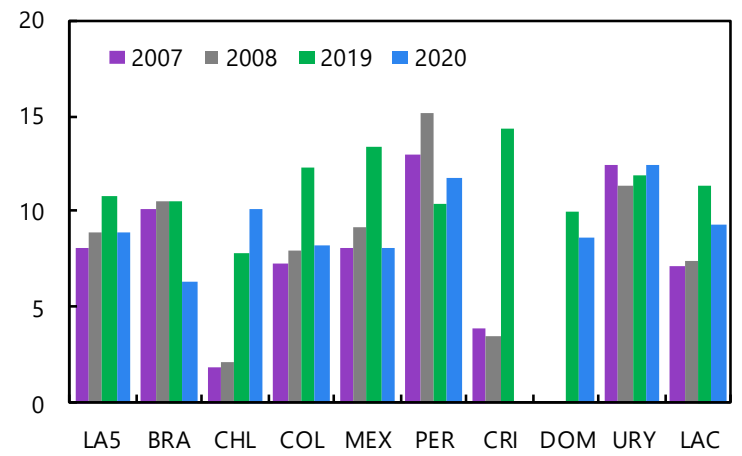

2. General Government Gross Debt: Denominated in Foreign Currency ${ }^{1}$ (Percent share of total gross debt)

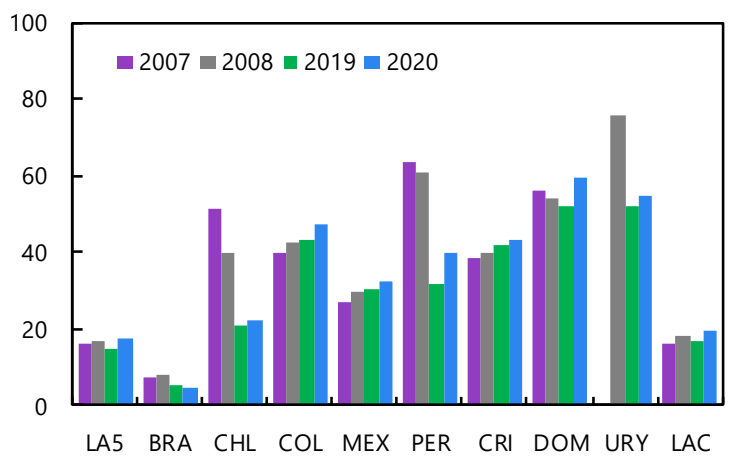

4. General Government Interest Payments ${ }^{1}$ (Percent of GDP)

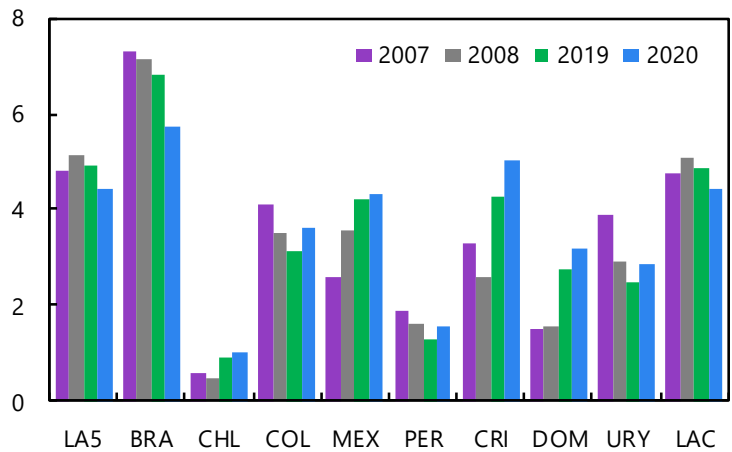

Sources: IMF, Fiscal Monitor (October 2020); IMF, Vulnerability Exercise (VE) database; IMF, World Economic Outlook database; and IMF staff calculations. Note: LAC (Latin America and the Caribbean) includes the countries shown in the chart. LA5 includes Brazil, Chile, Colombia, Mexico, and Peru.

${ }_{1}^{1}$ Aggregates are fiscal year US dollar nominal GDP-weighted averages.

2Data for 2007-08 and 2019 are from the VE database. Data for 2020 are from the Fiscal Monitor. Aggregates are simple averages.

On top of higher debt, the LA5 countries faced the COVID-19 shock with larger fiscal deficits and some of them with larger gross funding needs. For most countries, the larger deficits were a result of the collapse in commodity prices and the important slowdown in economic activity since 2013 , combined with domestic shocks-including social unrest, in 2019. In particular, Chile and Peru had large surpluses in 2008, that turned into deficits of 1-2 percent of GDP in 2019 (Figure 8). Despite suffering smaller terms of trade shocks, Brazil and Costa Rica faced deficits of about 6 percent of GDP in 2019. Gross funding needs were higher in 2019 than 2007 for Chile and Mexico, but somewhat lower for Brazil, Colombia and Peru (Figure 9, see also WHD-REO, Fiscal chapter).
Figure 8. General Government Fiscal Balance (Percent of GDP)

$$
\begin{aligned}
& 2019 \\
& \text { - Compatible with debt at } 60 \text { percent of GDP } \\
& \text { - Compatible with debt at } 40 \text { percent of GDP }
\end{aligned}
$$

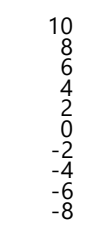

JAM PER DOM MEX COL CHL URY ECU PRY BRA C

JAM PER DOM MEX COL CHL URY ECU PRY BRA CRI २।

Sources: IMF, World Economic Outlook database; and IMF staff calculations.

Note: Definitions of government debt varies across countries. 
Figure 9. Gross Financing Needs (Percent of GDP)

\section{Global Financial Crisis, 2007-09}

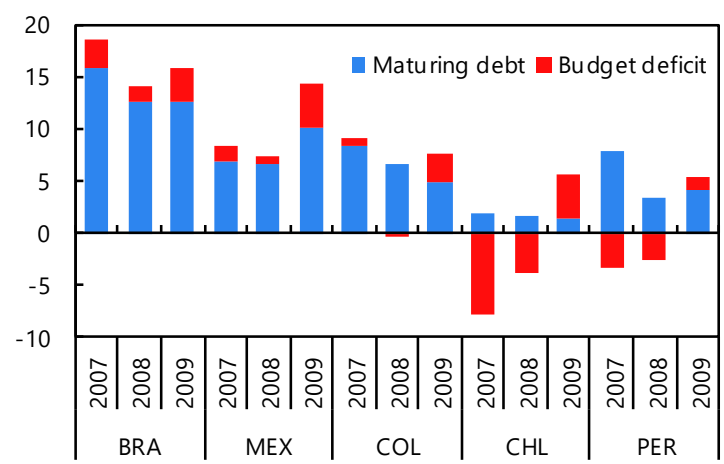

2. COVID-19, 2019-20

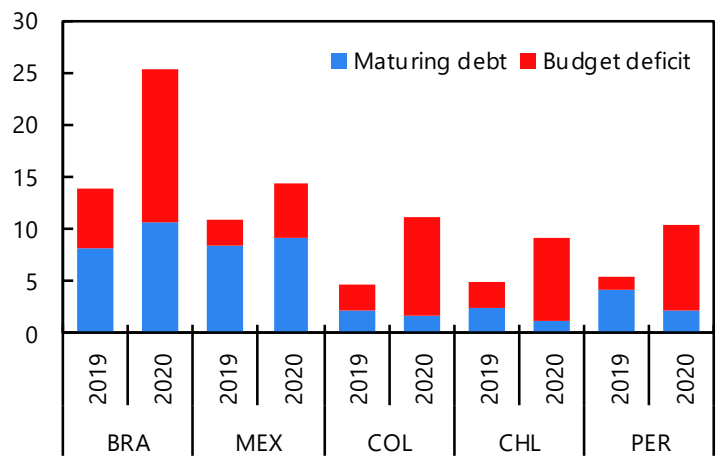

Sources: IMF, World Economic Outlook database; and IMF staff calculations.

While fiscal space appeared to be smaller before the COVID-19 shock, market access conditions were more favorable than in the wake of the GFC. LAC countries were showing somewhat weaker fundamentals by end2019, as summarized by their sovereign credit ratings (Figure 10). Before the COVID-19 shock some LAC countries had been downgraded, in part as a result of the collapse in commodity prices and associated weakening of fundamentals. Sovereign spreads for the region were roughly at the same level by end-2007 and end-2019 (at around 200 bps, see chart), suggesting similar access opportunities to international marketsalthough US Treasuries rates were around 300 bps lower in 2019, therefore leading to lower funding costs. These lower costs were driven by the secular decline in global rates. Figure 11 presents 10 -year rates for these countries, both in dollars and local currency, and effective interest rates, where it is evident that although fiscal fundamentals did deteriorate during the period, market access improved for most of these countries when measured through the cost of funding. After an initial tightening of financial conditions in February of 2020 , countries from the region were able to access international capital markets at unprecedented (favorable) terms and conditions.

\section{Figure 10. Credit Ratings and Sovereign Spreads}

\section{LAC: S\&P Ratings ${ }^{1}$}

(Number of countries as of end-2007 and end-2019)

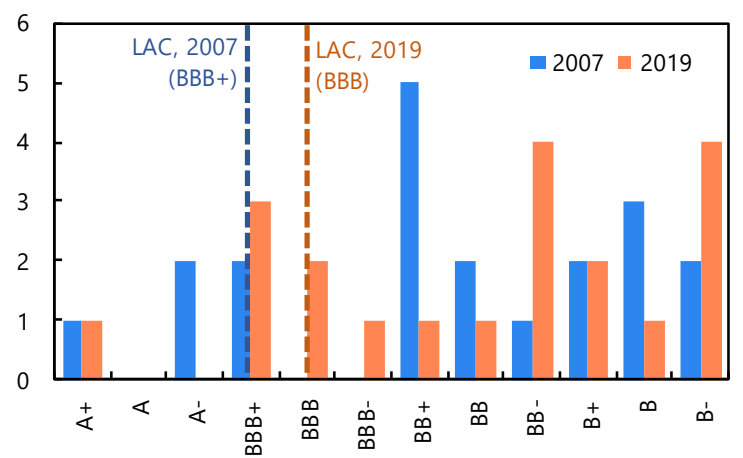

\section{LA6 Sovereign Spreads and US 10-Year Treasury Note Yield²}

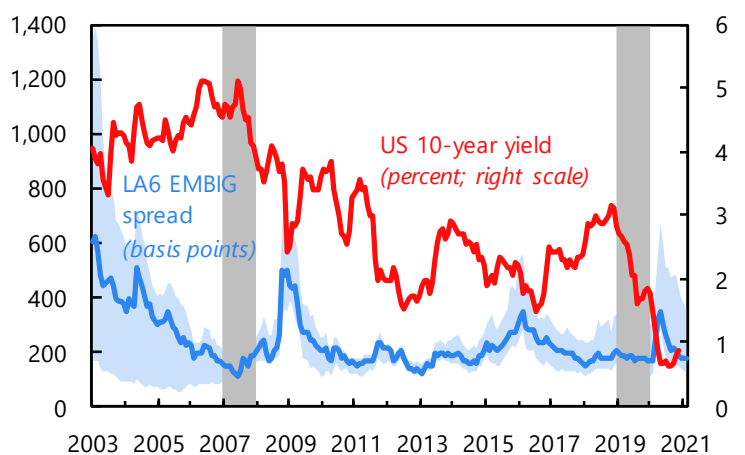

Sources: Bloomberg Finance L.P.; Haver Analytics; and authors' calculations.

${ }^{1} \mathrm{LAC}$ is the weighted average of the number of countries per rating and a numerical score that ranges from $1(\mathrm{~B}-)$ to $12(\mathrm{~A}+)$. Excludes Argentina and Venezuela. ${ }^{2}$ Sovereign spreads refer to the median of LA6 (Brazil, Chile, Colombia, Mexico, Peru, Uruguay) J.P. Morgan Emerging Market Bond Index Global spread; US-dollardenominated sovereign bonds. Shaded blue area refers to the min-max range. Shaded gray areas refer to pre-Global Financial Crisis (2007) and pre-COVID-19 pandemic (2019). 
Figure 11. Effective Interest Rates and Bond Yields (Percent of previous year gross debt; unless otherwise noted)

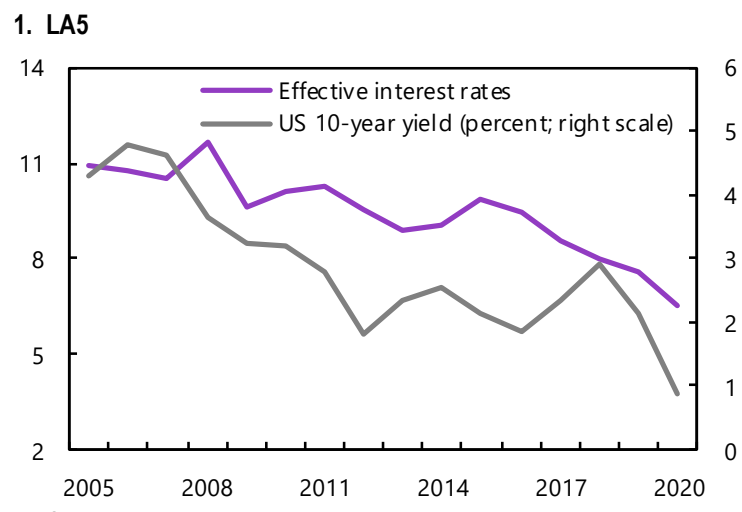

3. Chile

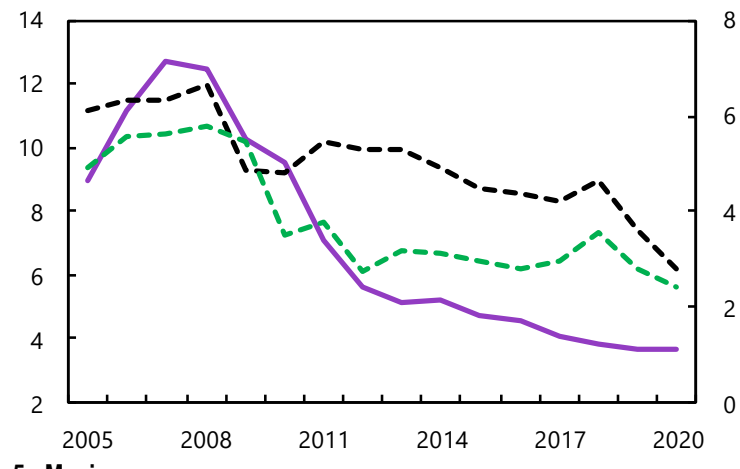

5. Mexico

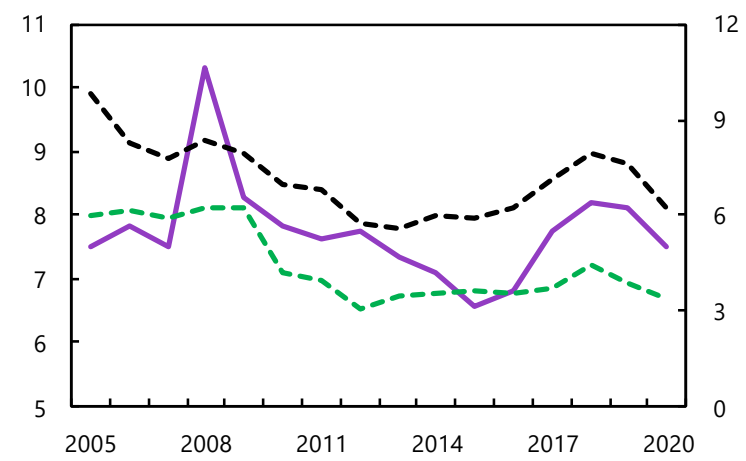

2. Brazil

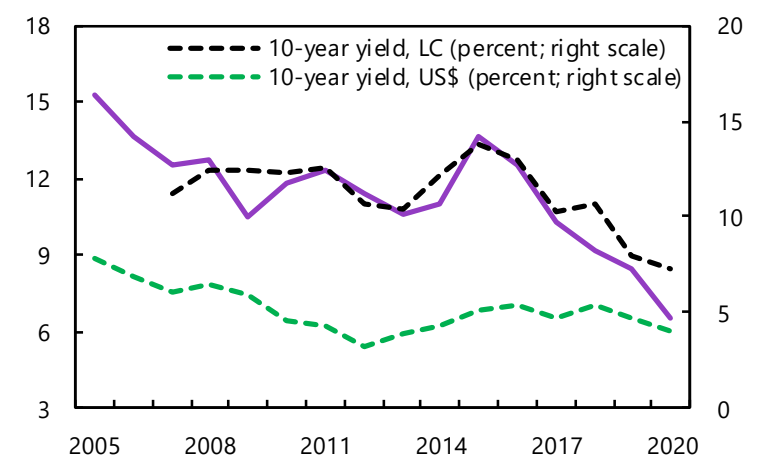

4. Colombia

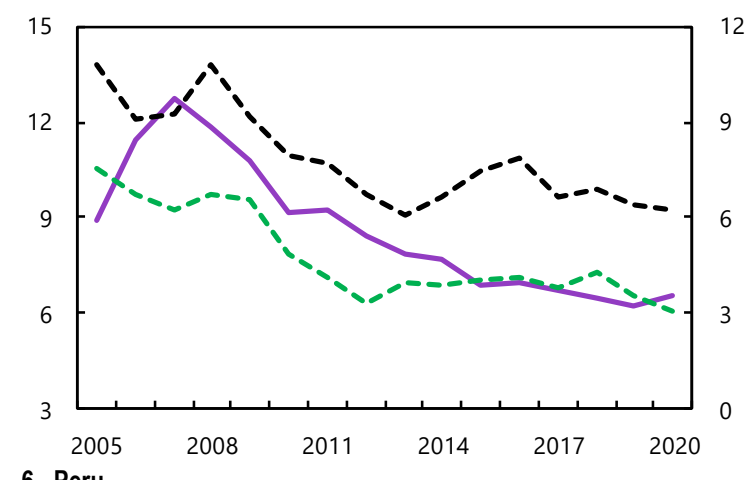

6. Peru

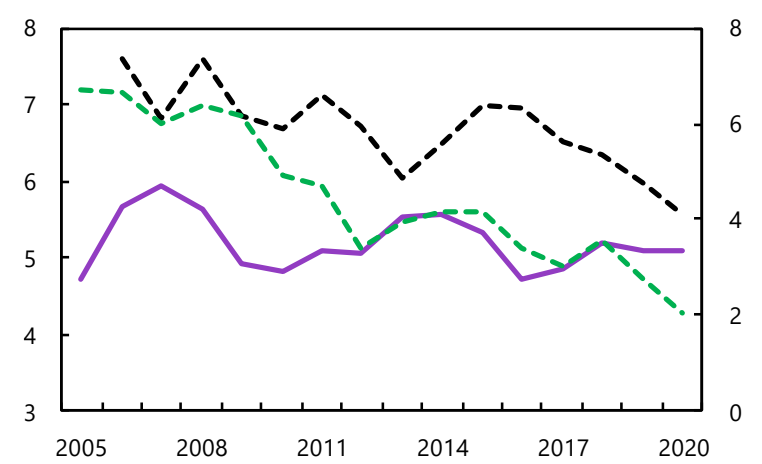

Sources: IMF, World Economic Outlook database; and authors' calculations.

Note: LA5 is fiscal year US dollar nominal GDP-weighted average of Brazil, Chile, Colombia, Mexico, and Peru. Ten-year US\$ yields were estimated by adding the US

10-year yield and each country's EMBIG spread for Chile, Colombia, Mexico (2005-09), and Peru (2005-15). 
In the end, the policy response to the COVID-19 shock was much larger than the one during the GFC, suggesting fiscal space was not as tight as expected (Figure 12). One key reason why fiscal space was larger than anticipated is associated with the secular decline in interest rates, that has compensated to a large extent for the higher debt. As Figure 11 shows, average government interest rates for LA5 countries fell from around 12 percent in 2008 to around 6 percent currently, more than the 4 percent decline in UST rates. This decline is particularly notable in Brazil, where effective interest rates came down from 13 percent to 6.5 percent in the same periods-as a result of the decline in both local and foreign currency interest rates. This sharp decline in interest rates has more than compensated the country's jump in the debt-to-GDP ratio from less than 65 percent of GDP to more than 95 percent, bringing the sovereign's interest payments to GDP ratio to a historic low of less than 6 percent (Figure 13). Despite recent increases in debt and interest payments in the other LA5 countries, the average interest payments-to-GDP ratio for the region has also fallen to a low of 4.5 percent. The larger policy response to the COVID-19 shock was needed and left a legacy of high government debt, but low-for-longer interest rates have increased fiscal space above previously estimated levels.

\section{Fiscal Policy in 2021 and Beyond}

The large fiscal response in 2020 supported incomes and activity but the persistence of the pandemic and wide output and poverty gaps, suggest that countries should avoid a premature withdrawal of support (Figure 14). Avoiding a large fiscal drag in 2021 with continued support, albeit at lower levels, would be an insurance policy for the recovery, especially now that there is less uncertainty about possible treatments and vaccines to control the pandemic. Moreover, as noted in the previous section, fiscal space may be larger than anticipated with low-for-longer interest rates and stable interest expenses. This section compares the assumed future fiscal consolidation in LAC countries with other EMDEs and argues that a more gradual path is feasible, especially since fiscal space is an endogenous concept that depends also on forward-looking commitments and the credibility of institutional frameworks that ensure countries would put debt on a downward path in the medium term.

The larger and more persistent output gaps in LAC versus other EMDEs, together with the disproportionate impact on vulnerable sectors of the labor market, suggest that the optimal, unconstrained fiscal response in 2021 would be the continuation, at lower levels, of income and other support measures for some time. In contrast to other recessions in the region (WHD-REO, October 2020), the current recession was associated with a larger decline in employment than in output (Figure 15). Moreover, the recovery in labor markets remains weaker than that in GDP. In line with these developments, poverty forecasts suggest that the expected removal of support in 2021 would lead to a reversal of the gains achieved in 2020—especially in Brazil. 
Figure 13. Gross Debt and Interest Payments (Percent of GDP)
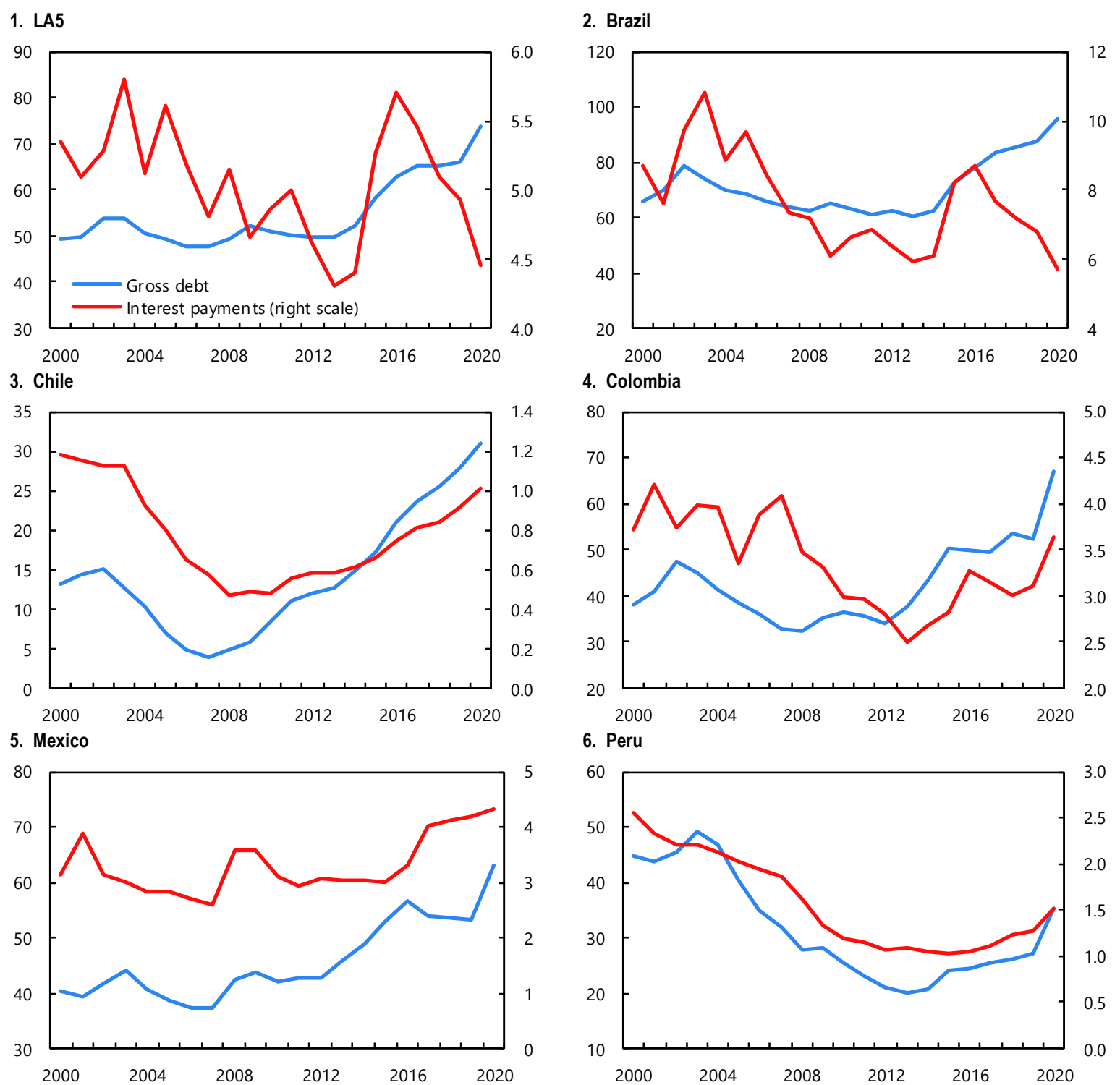

6. Peru

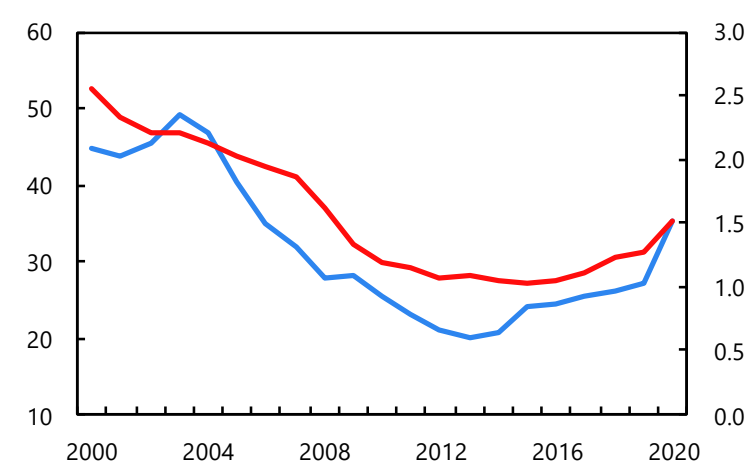

Sources: Consensus Economics; IMF, World Economic Outlook database; and authors' calculations.

Note: LA5 is fiscal year US dollar nominal GDP-weighted average of Brazil, Chile, Colombia, Mexico, and Peru. 
Figure 14. Output Gap

(Percent)

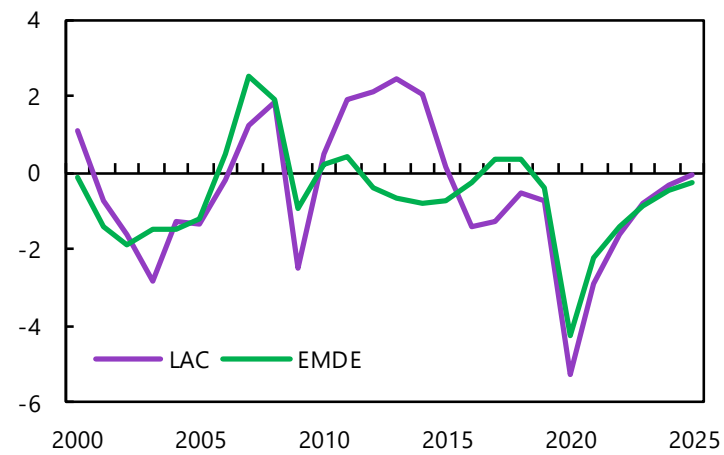

Sources: IMF, World Economic Outlook database; and IMF staff calculations. Note: Purchasing-power-parity GDP-weighted average of countries with data for the year. Each year may have different country sample. LAC excludes Argentina and Venezuela. EMDE excludes LAC countries.
Figure 15. GDP and Employment: COVID-19 Recession (Index: 2019Q4 = 100)

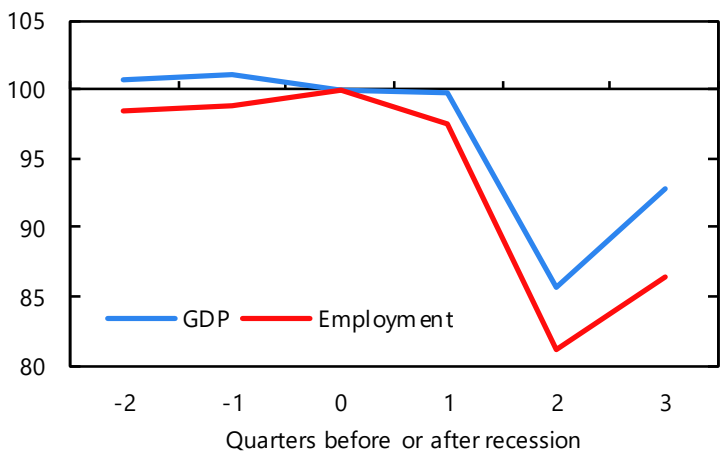

Sources: Haver Analytics; national authorities; and IMF staff calculations. Note: Includes Brazil, Chile, Colombia, and Mexico.

Still, concerns about fiscal space and debt sustainability could lead countries in the region to an early removal of support. ${ }^{5}$ In particular, policy responses under the announced packages suggest that the expected fiscal consolidation for 2021 and the near term is much larger than in other regions and also compared to what LAC has done in the past. We will argue that, with stronger commitments and institutional frameworks that ensure debt is put on a credible downward trajectory once the pandemic is under control, the region can afford to extend additional fiscal support in 2021 and maintain low interest rates and easy market access at the same time. Such more gradual consolidation will improve output, employment and poverty outcomes, while maintaining fiscal sustainability.

LAC countries faced the COVID-19 shock with higher initial debt levels than other EMDE. While the fiscal response to COVID-19 in 2020 in both groups of countries were similar, debt ratios jumped from 64 percent to 72 percent of GDP in LAC, while the corresponding increase in other EMDEs was from 51 to 60 percent of GDP (see Table 2). Projections using authorities' fiscal targets and WEO economic forecasts, suggest that debt ratios would stabilize in LAC while in other EMDEs they would continue to grow to around 67 percent in the medium term.

Table 2. EMDE versus LAC: Debt Sustainability

\begin{tabular}{|c|c|c|c|c|c|c|}
\hline & $2000-14$ & 2015 & 2019 & 2020 & 2021 & $2022-25$ \\
\hline \multicolumn{7}{|l|}{ Latin America and the Caribbean } \\
\hline Gross debt (percent of GDP) & 47.2 & 56.0 & 63.8 & 71.5 & 69.7 & 71.0 \\
\hline Primary balance (percent of GDP) & 1.3 & -1.6 & -0.3 & -6.2 & -1.9 & -0.3 \\
\hline Primary expenditure (percent of GDP) & 25.2 & 26.9 & 26.0 & 30.1 & 26.2 & 25.2 \\
\hline Total revenues (percent of GDP) & 27.3 & 25.5 & 26.7 & 24.7 & 25.1 & 25.4 \\
\hline Effective interest rate (percent) & 9.6 & 9.2 & 7.3 & 6.3 & 5.7 & 5.8 \\
\hline Nominal GDP growth (percent) & 10.0 & 5.0 & 5.0 & -3.7 & 8.4 & 6.2 \\
\hline $\mathrm{r}$ - g (percentage points) & -0.5 & 4.2 & 2.4 & 10.0 & -2.6 & -0.4 \\
\hline \multicolumn{7}{|c|}{ Emerging markets and developing economies } \\
\hline Gross debt (percent of GDP) & 39.3 & 41.0 & 51.2 & 60.4 & 62.9 & 67.2 \\
\hline Primary balance (percent of GDP) & 0.4 & -2.6 & -3.4 & -8.3 & -7.1 & -4.9 \\
\hline Primary expenditure (percent of GDP) & 24.9 & 28.9 & 29.3 & 31.8 & 31.1 & 29.8 \\
\hline Total revenues (percent of GDP) & 25.8 & 26.5 & 26.1 & 23.6 & 24.1 & 24.9 \\
\hline Effective interest rate (percent) & 4.6 & 3.2 & 3.3 & 3.0 & 3.0 & 3.2 \\
\hline Nominal GDP growth (percent) & 15.0 & 5.9 & 8.6 & 2.3 & 10.4 & 8.5 \\
\hline $\mathrm{r}$ - g (percentage points) & -10.4 & -2.8 & -5.3 & 0.8 & -7.4 & -5.3 \\
\hline
\end{tabular}

Sources: IMF, World Economic Outlook database; and IMF staff calculations.

Note: Latin America and the Caribbean (LAC) excludes Argentina and Venezuela. Emerging markets and developing economies (EMDE) excludes LAC countries.

\footnotetext{
${ }^{5}$ See, for instance, Sturzenegger (2020).
} 
The stabilization of debt levels in LAC is associated with a much sharper planned reduction in primary deficits and lower growth than in other regions. Primary balances in LAC are projected to rise from -6.2 percent of GDP in 2020 to -1.9 percent in 2021 and around zero over the medium term; whereas in other EMDEs they rise much more gradually, from -8.3 percent to -7.1 percent and 4.9 percent in the same periods (see Table 2). The more gradual removal of support in other EMDEs is associated with a much smoother reduction of primary expenditures than in LAC countries (Table 2), as well as with a more benign evolution of $(\mathrm{r}-\mathrm{g})$, which remains negative at around -5.3 percent, compared to a differential of around 0.4 percent in LAC (see Table 2 and Figures 16-17). In turn, the more benign evolution of the differential is mostly due to higher GDP growth in other EMDEs, consistent with their smoother contraction of primary spending.
Figure 16. Interest Rate-GDP Growth Differentials (Percentage points)

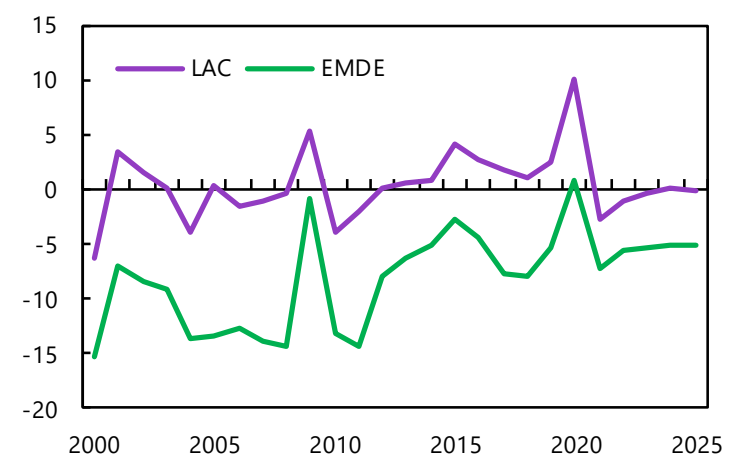

Sources: IMF, World Economic Outlook database; and authors' calculations. Note: Fiscal year US dollar nominal GDP-weighted average of countries with data for the year. Each year may have different country sample. LAC excludes Argentina and Venezuela. EMDE excludes LAC countries.

\section{Figure 17. Interest Rate and Nominal GDP Growth}

(Percent; excludes Argentina, Venezuela)
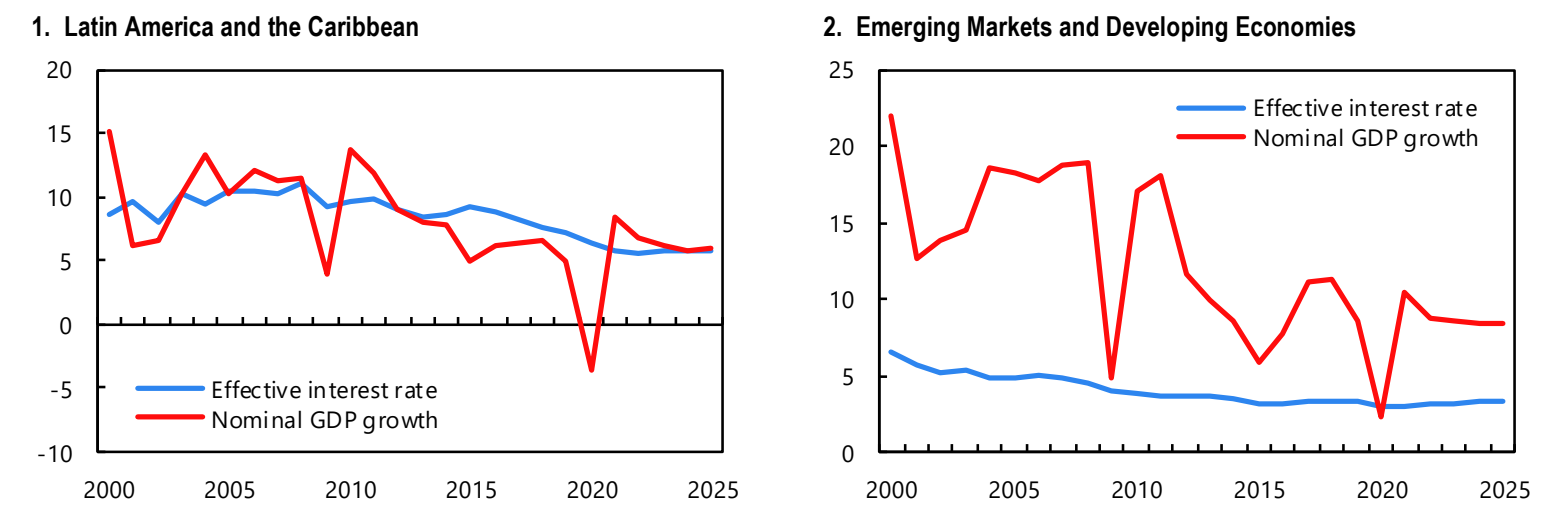

Sources: IMF, World Economic Outlook database; and authors' calculations.

Note: Fiscal year US dollar nominal GDP-weighted average of countries with data for the year. Each year may have different country sample.

The much sharper reduction of primary deficits and associated weaker growth performance in the region raises three questions. First, is it feasible to reduce the primary deficit in LAC by more than 4 percentage points of GDP this year? Second, is it desirable?. And third, what would be the risks associated with a more gradual strategy. 


\section{Feasibility of 2021 adjustment in the baseline}

One way to gauge the feasibility of achieving the assumed adjustment in the baseline is to look at what the region was able to do in previous episodes where there was a jump in debt levels (Figure 18). At the time of the Asian crisis, debt in LAC increased also by roughly 10 percentage points and the primary deficit was reduced by around 2 percentage points. Whereas in the GFC, debt-to-GDP in LAC increased by around 4 percentage points but the primary balance barely moved the year after the crisis, and increased marginally thereafter-while the debt ratio declined, as a result mostly of the rapid recovery in commodity prices and in activity in 2010-12. By these standards, the reduction in the primary deficit estimated for 2021, of more than 4 percentage points of GDP does not look that plausible, and failure to deliver could hurt credibility of the fiscal consolidation down the road.

\section{Desirability of the 2021 and near-term adjustment}

The large fiscal consolidation expected for 2021 is not just implausible but also it is not optimal under current imbalances in the LAC countries, a weaker recovery than after the GFC, and global financial conditions. A more gradual reduction of primary deficits might increase the debt-to-GDP ratio in the short run but deliver a better outcome in terms of growth, income distribution and poverty for 2021. More importantly, it may not lead to a significantly higher interest burden, as low-for-long interest rates compensate for the increased debt levels. Besides being sub-optimal and difficult to achieve by historical and cross-regional standards, the current consolidation path could also leave scars that may damage medium-term growth prospects and the actual debt dynamics. This section explores alternative consolidation paths that may provide better economic and social outcomes.

The extension of fiscal support into 2021, at lower levels than in 2020, could be facilitated by explicit, preferably legal commitments to consolidate once the pandemic is fully under control. This could be done by strengthening medium-term fiscal frameworks as detailed in the next sections.

Although the future consolidation will be a drag on growth and social conditions in the medium term, this would be done at a time when the economy is closer to potential (i.e., when output gaps are less than 2 percent and the labor market has delivered a stronger recovery). Even without considering potential scarring effects, this intertemporal shift in fiscal policy is likely to be superior to the current baseline path. Hypothetically, further cumulative support of say 5 percentage points of GDP in 2021-22, would smooth the adjustment in the region as a whole, closing the output and poverty gaps in a faster and less damaging way. Indeed, the fiscal 
consolidation could be spread over even more years under a credible institutional framework that puts debt on a downward path once the pandemic is under control.

Domestic and external conditions would be supportive of a more gradual consolidation path. On the domestic side, the nature of the COVID-19 shock has prompted an increase in precautionary (and forced) private saving, that could absorb locally the increased debt without crowding out much private investment (Figure 19). The pressures experienced in local markets in March subsided after the Fed's response on March 23. The persistence of easy global financial conditions suggests these pressures are unlikely to be repeated. On the external side, financial conditions remain very loose and countries have successfully tapped global markets at historically low yields - and several countries in the region have locked in low rates with very long duration issuances. For others, multilateral lending could be an alternative source of funding. In all, for most LAC countries with the exception perhaps of the Caribbean countries, public debt service is larger in local than in international markets (see Figure 19, right hand panel).

Figure 19. Savings, Investment, and Public Debt Service
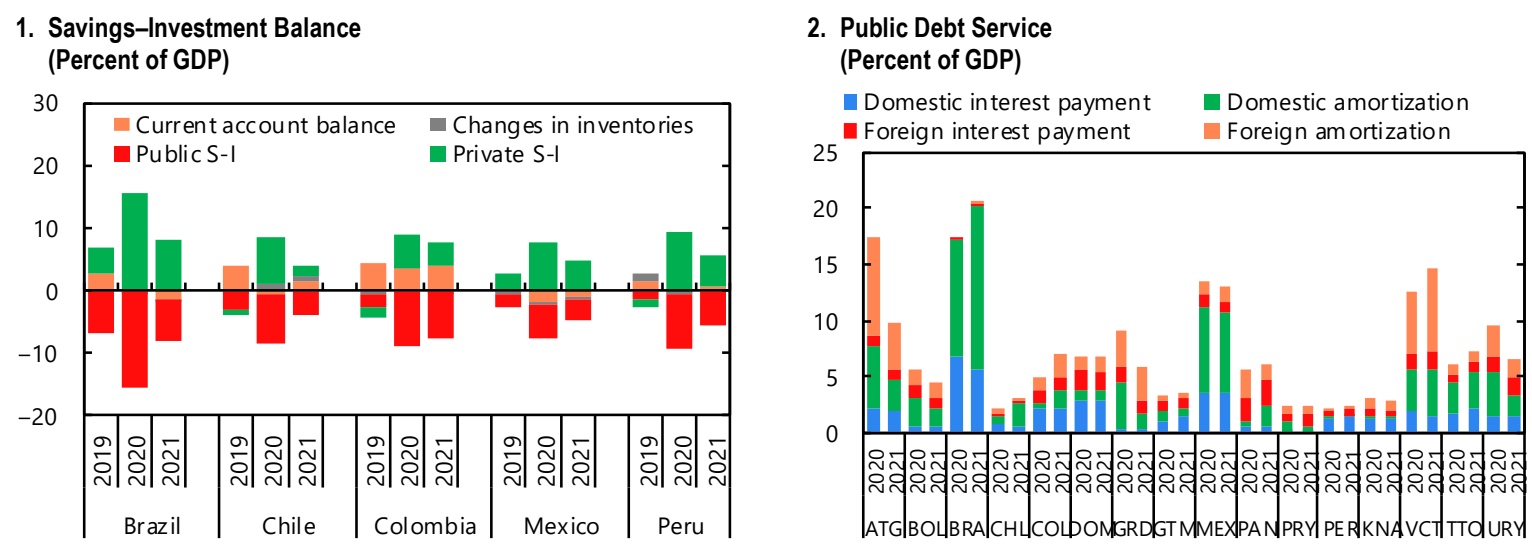

Sources: IMF, World Economic Outlook database; and IMF staff calculations.

More importantly, the low rate environment has contained interest payments and is leading to a reconsideration of fiscal policy priorities or benchmarks. As Figure 20 shows, LA5 countries have brought down interest payments to around 4 percent of GDP ( 2 percent for real interest payments) from almost 6 percent in 2015 (3.5 percent in real terms), despite a sharp increase in the debt-to-GDP ratio. ${ }^{6}$ And for most of the LA5 countries the lower rates continue to trickle down into lower average interest payments as recent issuances at very low rates (and long maturities) become more prominent in the averages. Furthermore, yield curves for the LA5 countries (Figure 21) suggest that rates would be around 150 basis points lower than prepandemic levels at least in 2021 meaning that countries could continue to keep a stable level of interest payments even with higher debt issuances. Moreover, debt management operations could lock in lower rates for larger shares of the stock of debt and maintain a lower interest burden even beyond the low-for-long rates period. With monetary policy reaching the limits of effectiveness, low rates for longer mean that countries may be less constrained by fiscal space as fiscal expansions themselves could improve sustainability by raising GDP more than debt and interest payments (Furman and Summers, 2020). At this historically very low rates, there real interest burden for the LA5 is around 2 percent of GDP, compared to around 1 percent of GDP in the US.

${ }^{6}$ And the decline is somewhat more pronounced and persistent for real interest payments. 
Figure 20. Gross Debt and Interest Payments (Percent of GDP)

1. LA5

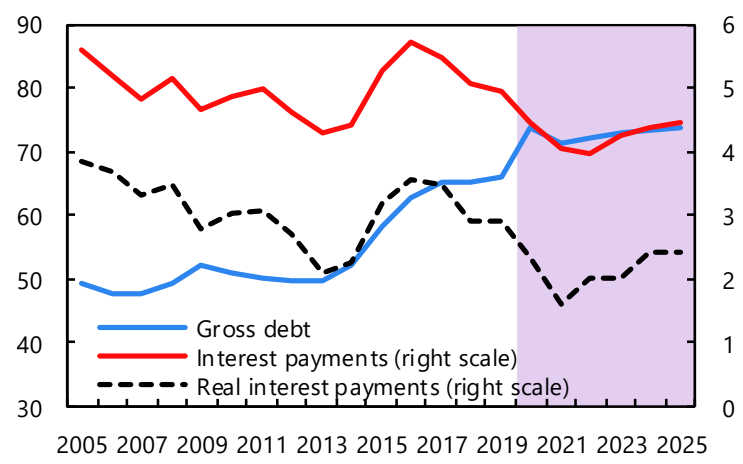

3. Chile

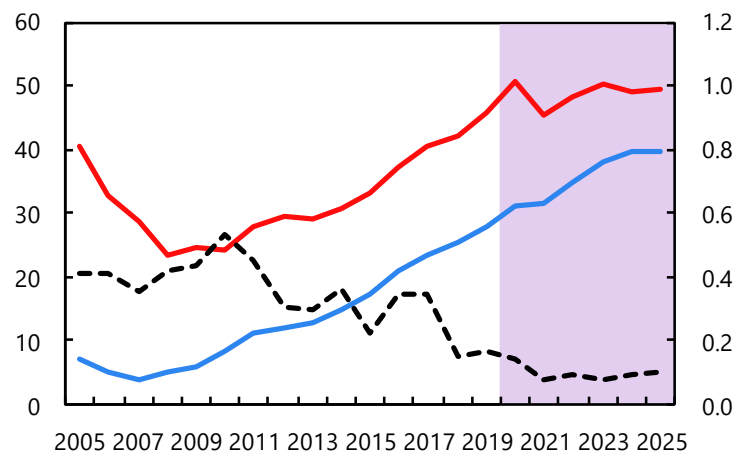

5. Mexico

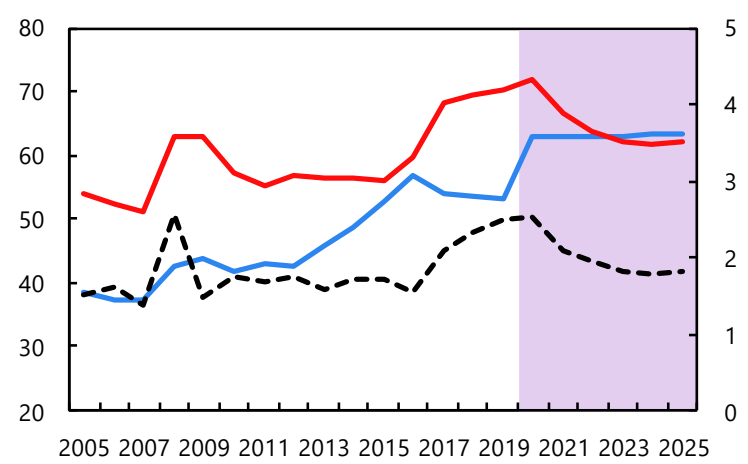

2. Brazil

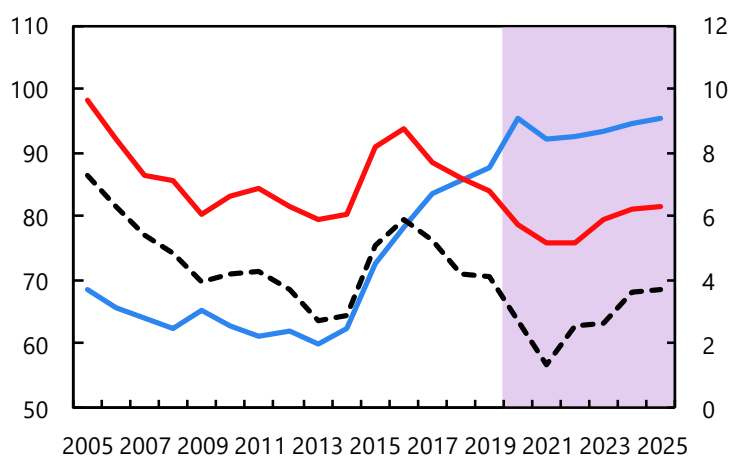

4. Colombia

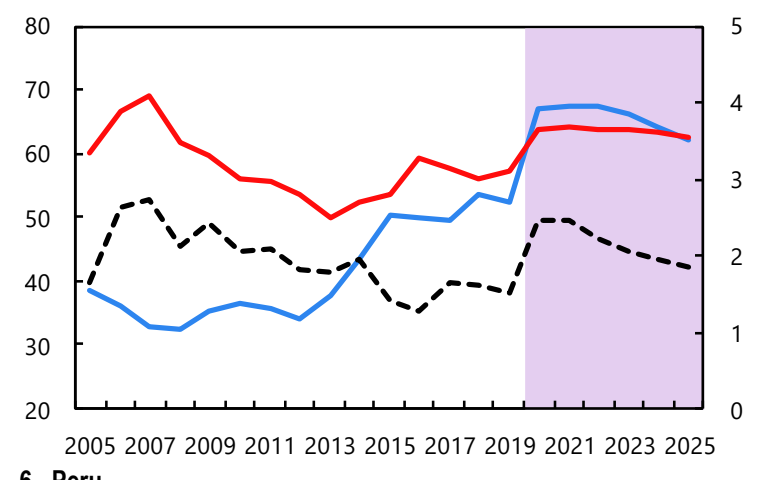

6. Peru

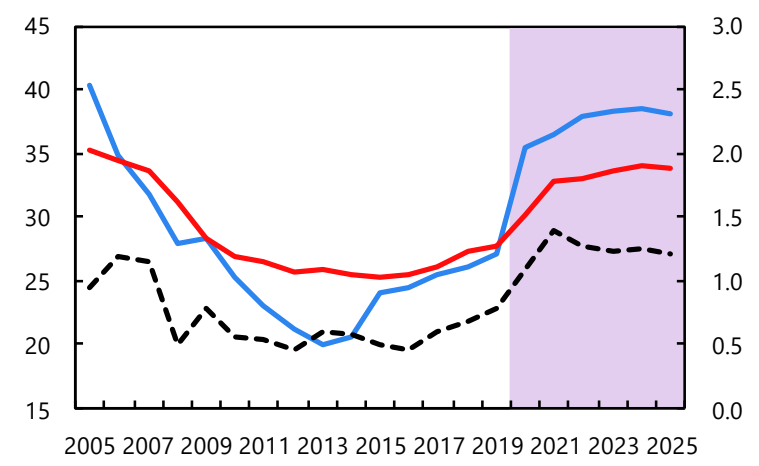

Sources: Consensus Economics; IMF, World Economic Outlook database; and authors' calculations.

Note: LA5 is fiscal year US dollar nominal GDP-weighted average of Brazil, Chile, Colombia, Mexico, and Peru. Real interest payments calculated using real interest rate (effective interest rate minus one-year ahead inflation expectations for 2005-20; minus WEO inflation projections for 2021-25). 
Figure 21. Sovereign Yield Curve, US dollars

(Percent)

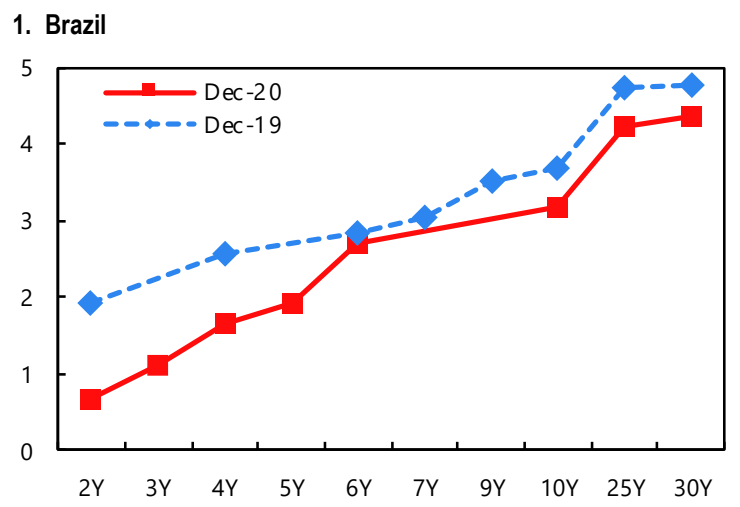

2. Chile

3. Colombia
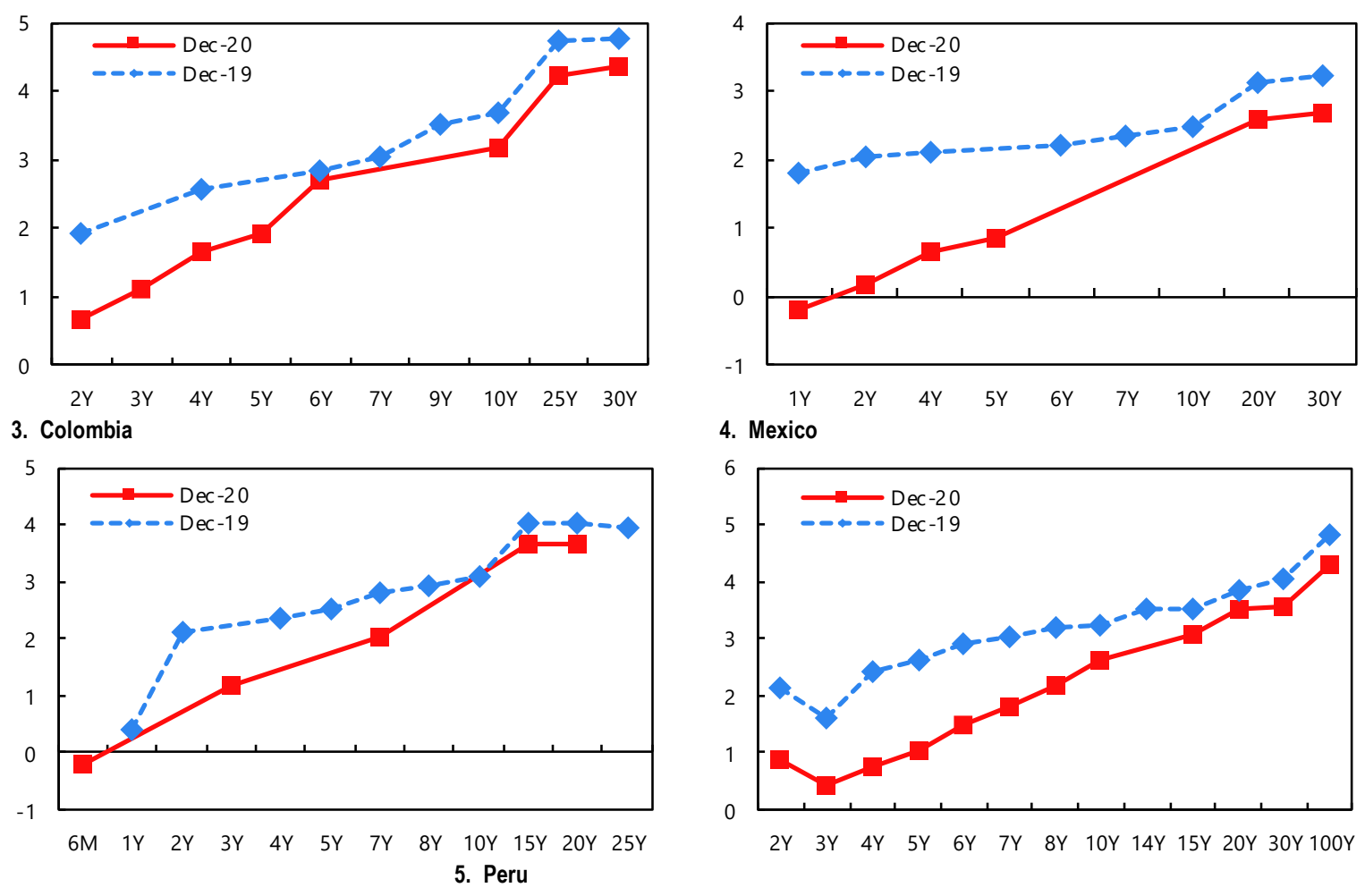

4. Mexico
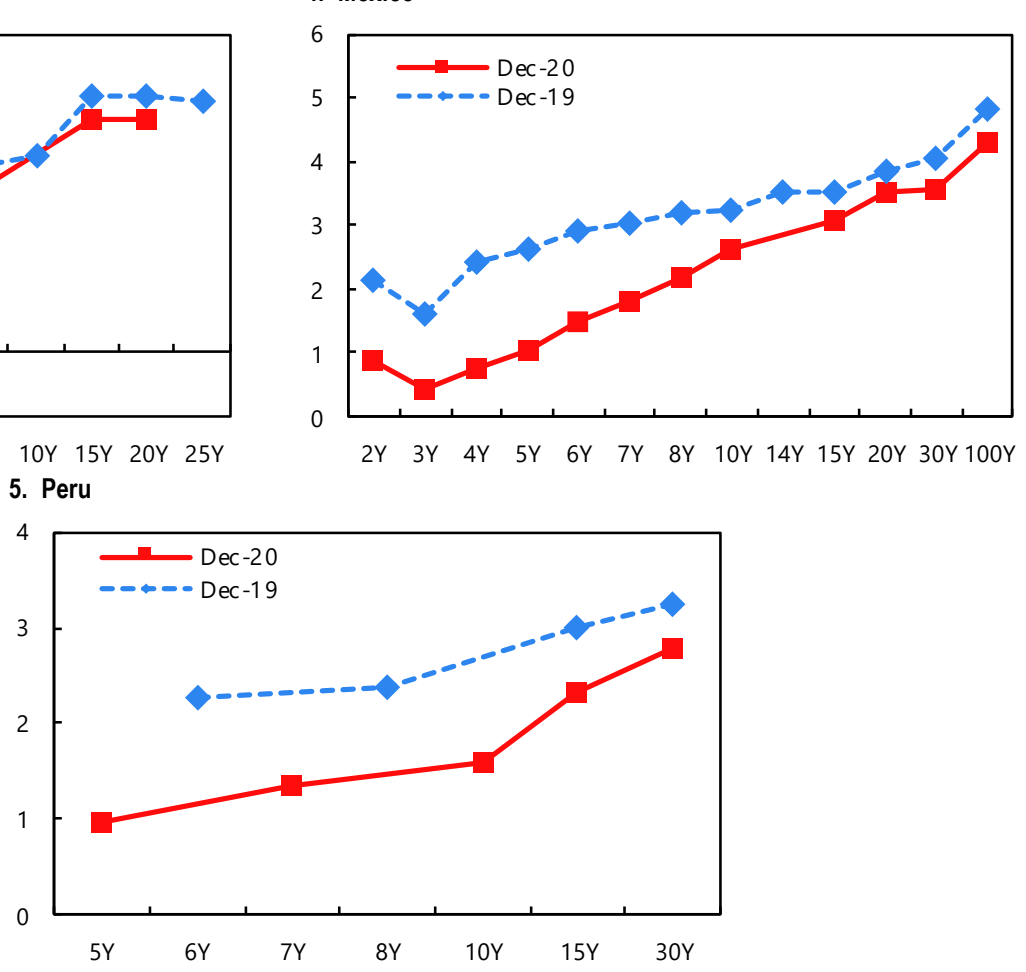

Source: Bloomberg Finance L.P.

A somewhat higher debt ratio may not increase funding costs or deteriorate credit ratings meaningfully in the short run. Empirical estimates from episodes of debt surges (Hadzi-Vaskov and Ricci, 2019); Hadzi-Vaskov and Ricci, forthcoming, suggest that a 10 percent of GDP increase in public debt is associated with an increase in sovereign EMBI spreads of 80-140 basis points in LA5 countries and a moderate deterioration in credit ratings (see also IMF, WHD-REO, Fiscal Chapter, Figure 17). However, the current episode suggests a somewhat smaller response in both spreads and ratings (Figures 22-23). Moreover, the rating agencies are internalizing the fact that the pandemic is a global shock and that it looks increasingly of a temporary nature. 
Figure 22. Sovereign Spreads

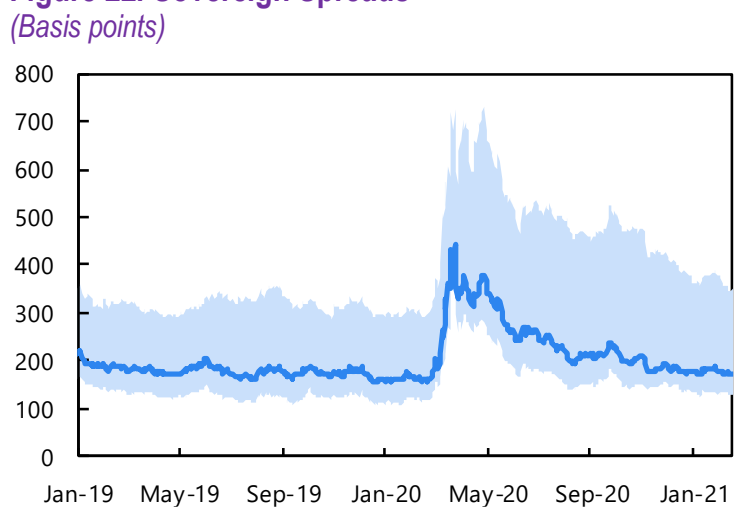

Sources: Bloomberg Finance L.P.; and authors' calculations. Note: Sovereign spreads refer to the median of LA6 J.P. Morgan Emerging Market Bond Index Global spread; US-dollar-denominated sovereign bonds. Shaded area refers to the min-max range of $L A 6$ sovereign spreads. $L A 6=$ Brazil, Chile, Colombia, Mexico, Peru, Uruguay.

As we argued before a more gradual path of fiscal consolidation coupled with the announcement of a small adjustment starting in 2023 is both feasible and desirable. To explore this more gradual consolidation scenario, we perform some illustrative simulations that add 3 (2) percent of GDP additional fiscal support in 2021 (2022), support that is removed with different degrees of gradualism in scenarios 1-3.7 While in scenario 1 the five percentage points of additional deficit are removed in 2023-24, the other two scenarios do it more gradually (see Annex for assumptions about impact on growth and interest rates/spreads). ${ }^{8}$ In all gradual scenarios the debt ratio peaks at around 75 percent of GDP in 2024 and then declines smoothly - to reach the 2020 debt-to-GDP ratio between 2028 and 2030 (Figure 24). More important, the ratio of interest payments to GDP moves marginally and stays broadly around 4 percent.

Moreover, the lower scarring associated with a more gradual consolidation could ensure a better growth trajectory and lower the debt-to-GDP ratio in the medium run under more gradual adjustment scenarios. To illustrate this possibility, we present next illustrative simulations that suggest is plausible to obtain a better evolution of GDP and debt under a more gradual consolidation path even with conservative assumptions about scarring. The simulations consider a scenario $\mathrm{A}$ (B) where the primary deficit is cut by 2 percentage points of GDP less (more) in 2021 and 1 percentage point less (more) in 2022. This scenario A is associated with higher GDP growth on those years, according to

${ }^{7}$ These are illustrative scenarios for an "average" LAC country, not specific advise for individual countries.

${ }^{8}$ Compared to the baseline scenario in Table 2, the primary balance would fall from -6.2 percent of GDP in 2020 to -4 percent of GDP in 2021 and -2 percent in 2022-more in line with the gradual adjustment envisaged in the forecasts of other EMDCs.
Figure 23. Gross Debt versus S\&P Credit Rating (Change; 2015-20)

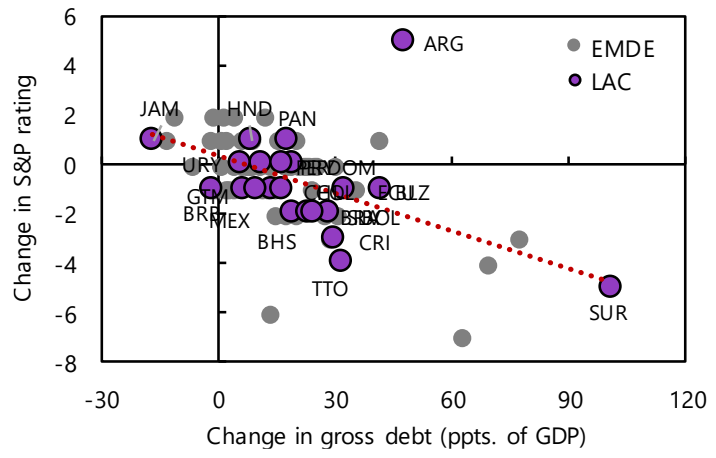

Sources: Bloomberg Finance L.P.; and IMF, World Economic Outlook database. Note: Numerical equivalent of S\&P credit ratings was used, which ranges from 0 to 22 (D to AAA).

Figure 24. Gradual Fiscal Consolidation (Percent of GDP; multiplier $=1.0$ )

\section{Gradual Fiscal Consolidation}

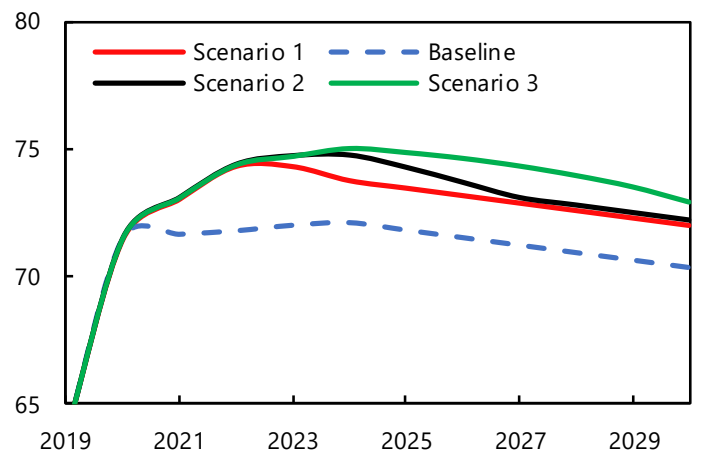

2. Interest Expense

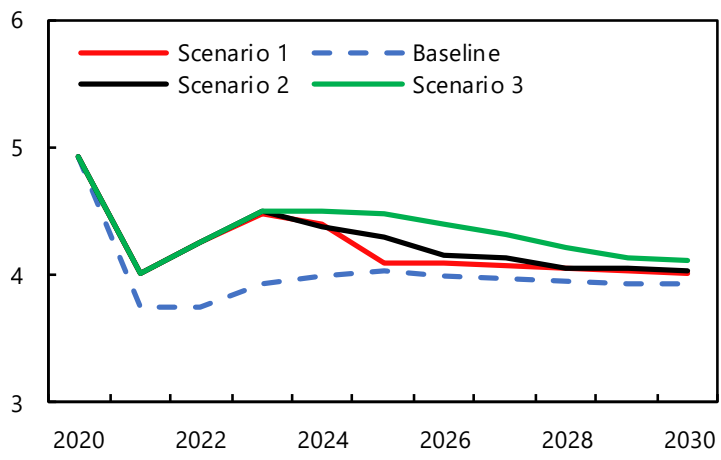

Sources: IMF, World Economic Outlook database; and authors' calculations. Note: LAC excluding Argentina and Venezuela. 
two different fiscal multipliers: a multiplier of 1 and one of 1.33. The latter scenario, presumably with a bigger public investment component, yields a slightly higher debt ratio in the near term, but delivers better debt dynamics in the medium term (and growth performance overall). The same scenario but with a multiplier of 1, also dominates the debt dynamics of the baseline but in a longer horizon, i.e., towards 2029 instead of 2026 (Figure 25). ${ }^{9}$ In both scenarios, interest payments remain very close to 4 percent of GDP.

Figure 25. Alternative Fiscal Policy and Debt Scenarios

\section{(Percent of GDP)}

\section{Multiplier $=1.33$}

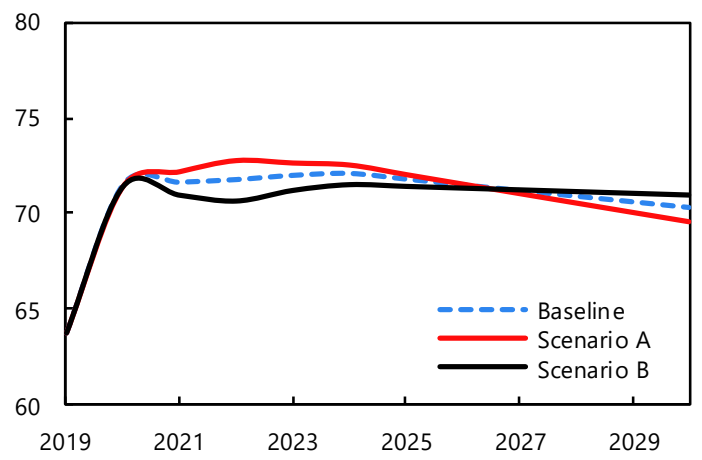

3. Interest Expense (Multiplier $=1.33$ )

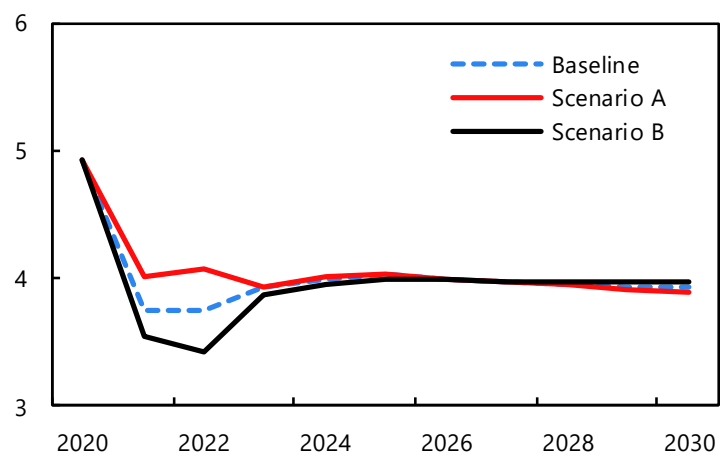

Sources: IMF, World Economic Outlook database; and authors' calculations. Note: LAC excluding Argentina and Venezuela.

\section{Risks to a more gradual consolidation path}

A more gradual path to consolidation is not without risks: growth will be better but the window of opportunity due to low interest rates may narrow earlier than expected..$^{10}$ Yet a battery of stress tests suggests these would be manageable. The fan chart below shows that, based on the joint statistical distribution of growth, primary balances and interest rates, worse case scenarios would increase the average debt ratio for the LAC region to a range of around $78-85$ percent of GDP, around 10 percentage points from current levels (Figure 26). But this is a low probability event, and corrective measures could be applied in such an event.

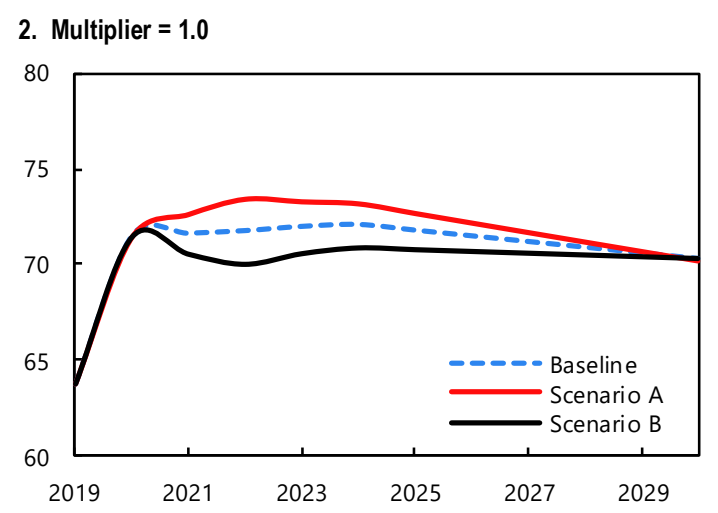

4. Interest Expense (Multiplier $=1.0)$

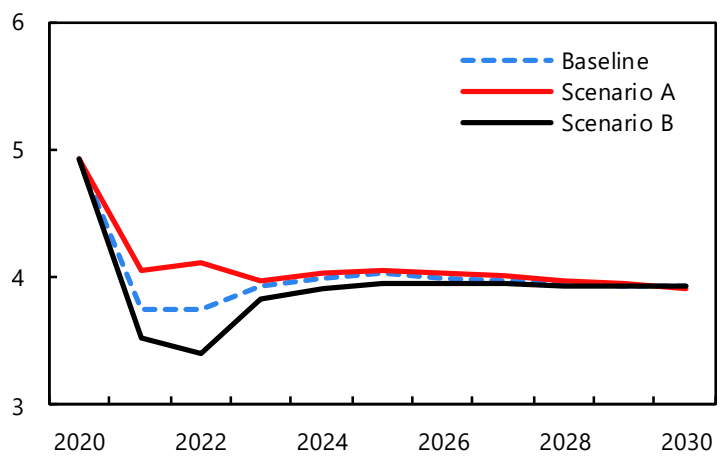

Figure 26. Evolution of Debt-to-GDP Ratio (Percent)

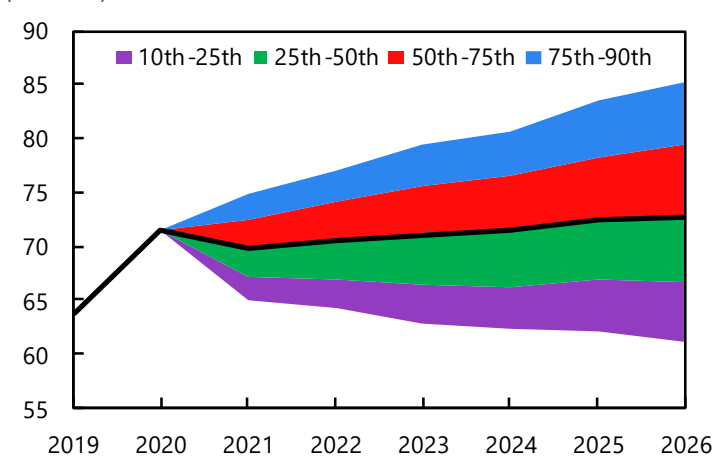

Sources: IMF, World Economic Outlook database; and authors' calculations. Note: LAC excluding Argentina and Venezuela.

${ }^{9}$ The avoidance of scarring, both in physical and human capital, is assumed to yield 0.5 percent extra GDP growth in 2023 and 0.3 percent extra growth in 2024-30 (see also Aziz et al, 2020).

${ }^{10} \mathrm{On}$ the implications and risks associated with $(\mathrm{r}-\mathrm{g})<0$, see Mauro and Zhou (2020). 
Only an extreme tail risk scenario, one where the region faces a combined three-standard-deviation shocks to interest rates, growth and primary balances, would send the debt ratio above 100 percent of GDP

(Figures 27-28).

Figure 27. Gross Public Debt: One Standard Deviation Shock (Percent of GDP)
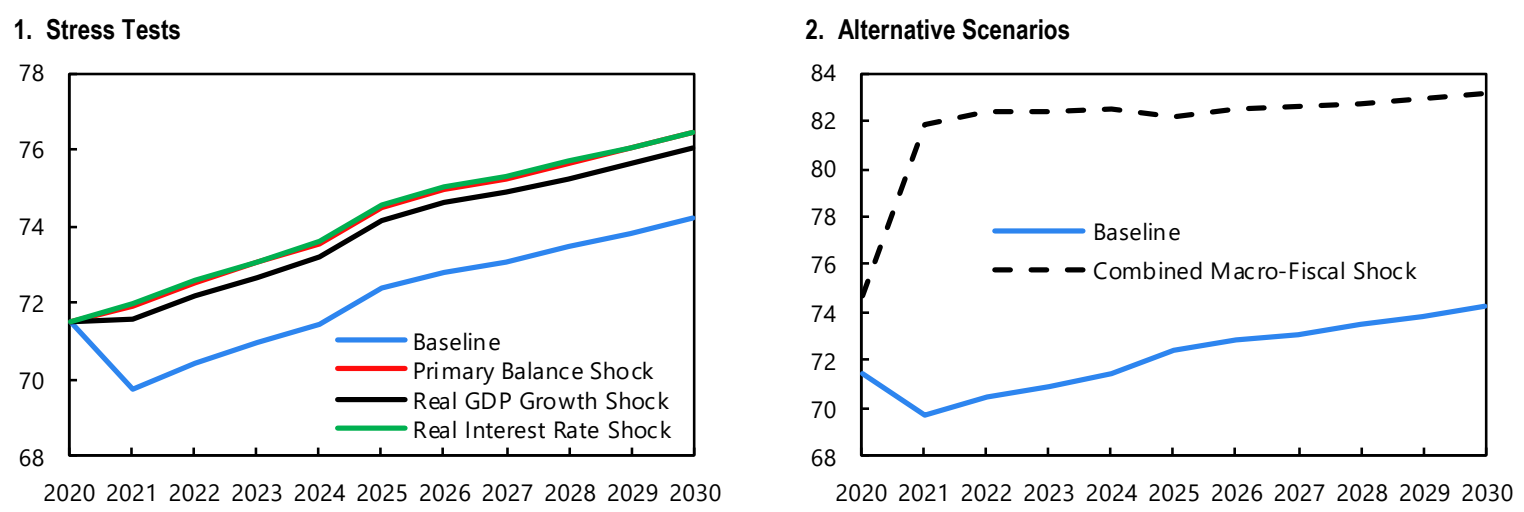

Sources: IMF, World Economic Outlook database; and authors' calculations. Note: LAC excluding Argentina and Venezuela.

\section{Figure 28. Gross Public Debt: Three Standard Deviation Shock}

\section{(Percent of GDP)}

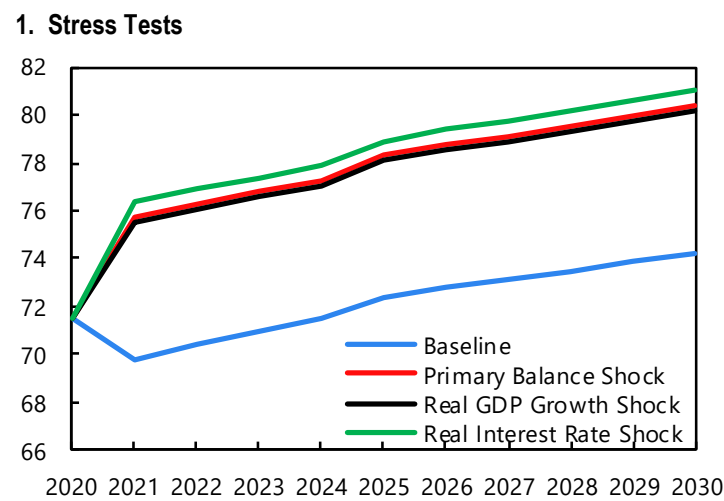

Sources: IMF, World Economic Outlook database; and authors' calculations. Note: LAC excluding Argentina and Venezuela.

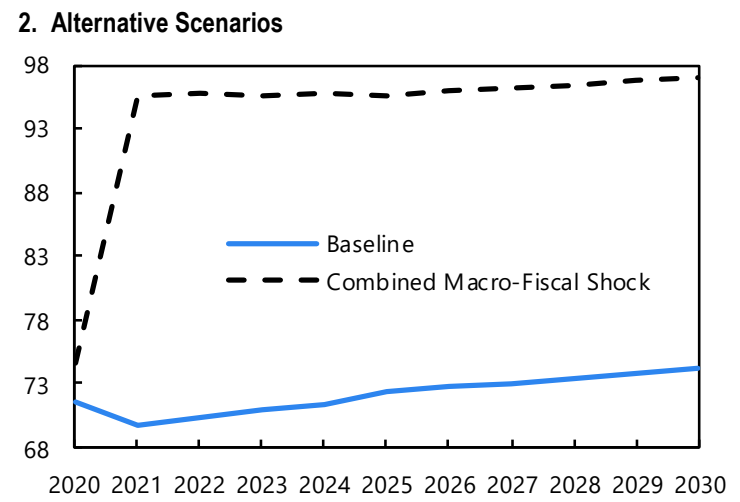

\section{Bottom line}

These simple exercises suggest that most countries should avoid an early and sudden withdrawal of support in 2021. Initial conditions and financial and institutional constraints vary across countries, so this policy path may not fit all—these illustrative exercises were conducted for an "average" LAC country. Still, if complemented with a strong set of institutional reforms that strengthen fiscal anchors over the medium term, a more gradual fiscal consolidation path could improve macroeconomic and social outcomes. And, in particular, a better growth performance could facilitate other complementary measures - such as those detailed in the next sections, that would put debt on a downward trajectory a few years down the road.

As noted in the introduction, these alternative fiscal and other measures could be adopted in the context of the first stage of the fiscal pact. This pact would have to tackle the necessity to continue to support households and firms during the next stages of the pandemic, while preserving favorable market access conditions by guaranteeing a strong medium term fiscal anchor and credibly communicating a clear path on how fiscal targets are going to be reached once the pandemic fades away and the economy goes back to potential. There may be technical and political challenges to achieving this first stage of the fiscal pact but it would be an important institutional mechanism to strengthen the commitments to future consolidation. 
Moreover, this fiscal discussion has to tackle the medium-term challenges of broadening the social safety net and improving the quality of public services, while also guaranteeing the medium-term sustainability of public finances and the build-up of adequate buffers to cope with possible future shocks. The next section outlines some of the broad ingredients of a redesign of the public health, education, and pension frameworks, as well as potential rationalizations of expenditure and tax systems. ${ }^{11}$

\section{Progressivity, Expenditure and Tax Options}

As argued in the previous section a more gradual fiscal consolidation in 2021-22 would avoid an early withdrawal of support for households and firms in the last stages of the pandemic in which the contagion rates continue to be very high and vaccination roll out is in its very early stages in almost every country in the region and the economic recovery is uneven, uncertain and its costs biased towards the most vulnerable. Therefore, as discussed in the introduction, this first stage of the fiscal pact is focused in implementing a gradual exit from emergency support and in targeting better some of the emergency measures adopted in 2020 , dealing with the legacy effects of the pandemic on poverty and inequality as well as taking initial steps to improve revenues and reallocate expenditures. In a second stage, after the pandemic is over, countries should improve social protection by revising access to pensions, health, and educational systems as well as reforming tax frameworks to increase revenues (in the cases were this is needed) and deliver a higher degree of progressivity from public finances in the region. This second stage of the fiscal pact would align the role of the state in Latin America with regional development levels and societies preferences as reflected in recent social movements and political developments.

Stage 1: Continued support to struggling families and firms and start dealing with the legacy effects of the pandemic on poverty and inequality

An effective strategy to contain and reverse the losses in terms of employment, poverty and inequality-while also making progress in terms of gradual fiscal consolidation-needs to combine the generation of good quality jobs-jobs that pay well, have some stability, and provide access to social insurance and core labor protections-while at the same time gradually phasing out and improving the targeting of the key support programs introduced in 2020 as a response to the pandemic. The total fiscal effort should be smaller than in 2021 and it should gradually shift towards promoting formal job creation and supporting aggregate demand. On the income side, authorities need to quickly move to implement administrative measures that improve tax collection and legislate some tax changes to come into effect in the second half of 2021 and in 2022 on digital and property taxes, as well as in making the PIT more progressive.

Regarding employment protection mechanisms, interventions have been varied during the preservation phase. Credit guarantees and direct subsidies to payrolls have been two common mechanisms, together with the deferral and suspension of payroll taxes and contributions. However, employment protection programs have focused primarily on formal workers. Protection of informal workers' incomes has been done mostly though cash transfers to individuals. The challenge now is to transition to interventions that support the generation of job opportunities for the unemployed or underemployed.

\footnotetext{
${ }^{11}$ It is not the objective of this paper to tackle in detail the broader agenda of the second stage of the fiscal pact.
} 
Measures that could create space in the near term are associated to the concept of leakages, which takes the form of outright corruption and also of expenditures that are diverted to less efficient uses. The IDB estimates that cost-overruns in public spending, high salaries and bad targeting of social programs and policies cost the region 4.4 percent of GDP (Figure 29). ${ }^{12}$ Improving the targeting of social programs requires new and more robust ways to estimate household incomes, addressing implementation errors, fraud, and corruption in the allocation of transfers. Other leakages are caused by tax exemptions that disproportionally benefit rich individuals. The IDB estimates that LAC could save 1.7 percent of GDP by removing the leakages in social programs, especially those that are not well targeted, such as tax exemptions for basic goods and services and fossil-fuel subsidies. The leakages correspond to nearly half of the total expenditure in these programs.
Figure 29. Technical Inefficiency in Targeted Transfers, Procurement, and Wage Bill (Percent of GDP)

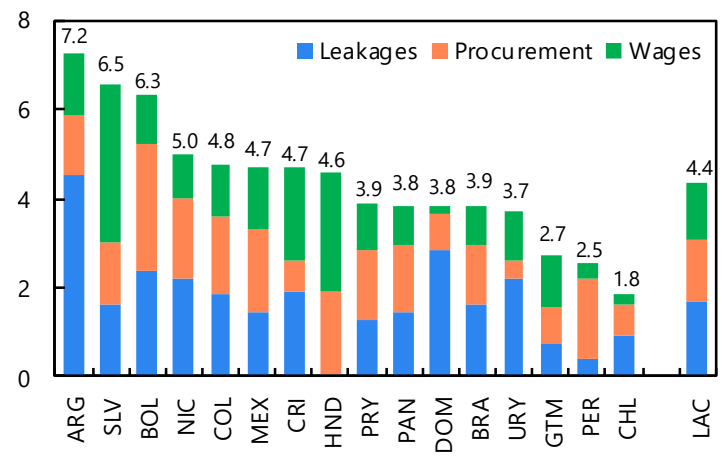

Source: Inter-American Development Bank.

Note: For most countries, the data correspond to year 2015 or 2016 or the latest available.

\section{Stage 2: Renewing the social contract}

Once the pandemic is under control, countries should improve social protection by revising access to pensions, health, and educational systems as well as reforming tax frameworks to increase revenues (in the cases were this is needed) and deliver a higher degree of progressivity from public finances in the region. As noted in Arze del Granado et al (2018, see Figure 30), fiscal policy has contributed to reductions in inequality in LAC countries to a similar extent than other EMDEs-but less so than in AE. The region outperforms other EMDCs in terms of spending in education and health, but access and quality need to be improved. However, the region's direct tax and cash transfer systems have been less effective in reducing income inequality than elsewhere (see also IMF-WHD-REO, 2020, Chapter 4). These are the main areas a renewal of the social contract would contribute to more equitable and sustainable public finances.

\section{Enhancing Social Protection}

The scars from the COVID-19 pandemic have created awareness about the importance of safeguarding social protection and the weakness of existing automatic stabilizers - such as progressive income taxes, unemployment benefits, and social safety nets. Unemployment benefits and unemployment insurance are almost inexistent in the region, leaving the burden of social protection during harsh circumstances to social safety nets (SSNs). During the pandemic, liquidity-constrained households were not able to smooth their consumption more effectively, exacerbating social tensions which are beginning to emerge again in the region. These shortcomings of the SSN that became evident during the pandemic are in addition to those existing pre-pandemic and that were behind the recent social tensions. These pre-pandemic shortcomings are associated with poor coverage and low replacement rates of pensions and low quality and deficient coverage in health and education systems. Therefore, this second stage will have to redesign the SSN and the current tax and expenditure systems to make them more progressive and increase their coverage and quality of services.

\footnotetext{
12See Izquierdo et al, 2018.
} 
Figure 30. Reduction in Income Gini from Direct and Indirect Fiscal Instruments (Percent)

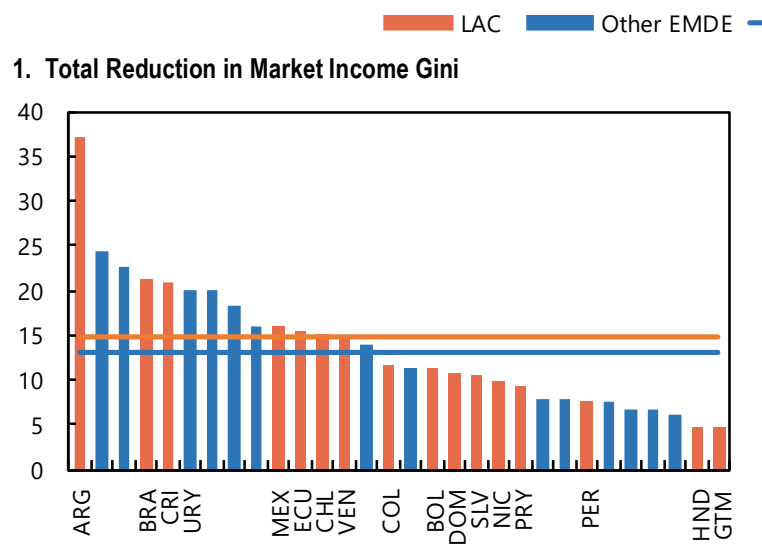

3. Indirect Taxes and Subsidies
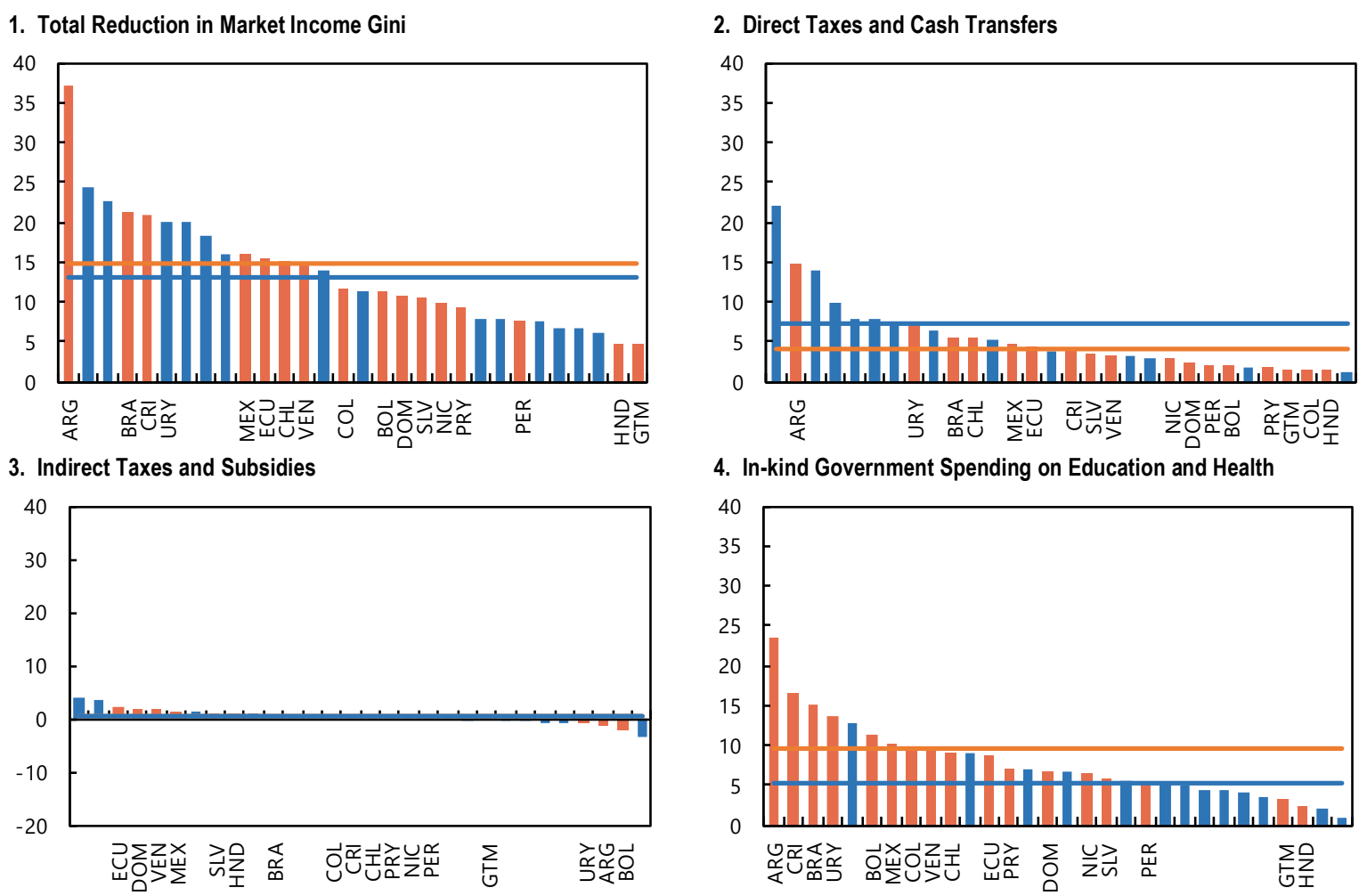

Source: Based on data from Lustig, editor, 2018. Commitment to Equity Handbook. Estimating Impact of Fiscal Policy on Inequality and Poverty.

Note: LAC (Latin America and the Caribbean) includes Argentina, Bolivia, Brazil, Chile, Colombia, Costa Rica, Dominican Republic, Ecuador, El Salvador, Guatemala, Honduras, Mexico, Nicaragua, Paraguay, Peru, Uruguay, and Venezuela. Other EMDE (emerging market and developing economies) includes Armenia, Ethiopia,

Georgia, Ghana, Indonesia, Iran, Georgia, Ghana, Indonesia, Iran, Jordan, Russia, South Africa, Sri Lanka, Tanzania, Tunisia, and Uganda.

The pandemic has underscored the need to upgrade social protection in LAC. In particular, SSNs have significant gaps in terms of coverage of lower income groups, while benefit levels (generosity) are insufficient in order to prevent an increase in poverty (Hannan, Honjo, and Raissi, 2020). Programs are often fragmented, involve beneficiary overlaps, and lack appropriate incentive features.

In addition, SSNs' impact can be improved by expanding coverage in a cost-effective manner through proxymeans targeted transfers, whereby targeting is improved by giving households a score based on a statistical algorithm that predicts incomes or consumption or poverty, such as Sisben IV in Colombia. Duplications need to be addressed once countries strengthen their administrative capacity.

Expenditure efficiency is a crucial step. Reducing the number of programs with multiple and conflicting objectives, the duplication of beneficiaries, and the excessive operational costs should be assessed. This a unique opportunity to phase-out interventions with sub-par outcomes and substitute them with programs with scale economies and better incentives. Asset mobilization is another dimension to consider.

Transforming unproductive assets into investments with a higher internal rate of return would be particularly advisable in the post-pandemic scenario.

Finally, on the operational side, mobile money to assure expedite, low-cost, low-contact transfers, but also traceability of its use can have several positive effects. Beneficiaries can build a history of payments that would enable them to become eligible for credit. Use of big-data can be complemented with better methods to design in-kind transfers such as education and health, use of existing social registries where applicable, and use of community-based methods to identify those in need. 


\section{Raising Revenues}

An expansion of government revenues is necessary in order to ensure fiscal sustainability and bring LAC revenues more in line with other emerging markets (Figure 31). As noted in section IV, this could be done by pre-announcing - even pre-approving, tax reforms that put debt on a sustainable trajectory after 2022, but some measures on the revenues side could be adopted before that year. In particular, policy and administration actions that could improve VAT, corporate and personal income tax performance could be adopted in the short run. Urgent steps are rationalizing inefficient and regressive income tax expenditures and widening the top personal income tax bracket, which would strengthen the progressivity of income tax systems. In addition to reforms to personal income taxes, property taxes and broader VAT bases can play an important role. In this regard, there is significant scope in tax reforms in several LAC countries, including Colombia, Mexico, and Peru.

It is also desirable to decouple social security coverage (such as health) from the type of employment—and finance it with general taxes_-eliminating the burdens that today fall on formal workers. The workerregardless of the type of labor relationship - must contribute with personal income tax, but not with a special contribution based on the employment status.

Considering that for some LAC countries energy subsidies represent very high percentages of their GDP (ranging from 4 percent to over 16 percent for the 10 countries with highest such percent in LAC), reducing them is a top priority. Adopting a carbon tax could be a natural first step, that would generate revenues of relevance.

Digital taxes should be another source of revenue. Even if there is no international agreement and consensus, LAC countries should implement the recommendations made by the OECD to the G-20. Finally, property taxes are generally very low in LAC. This is an area where significant progress can be made, beginning with the implementation of new cadastral technologies that can be updated more frequently, and that provide a better assessment of property values.

\section{Expenditure measures}

Future fiscal consolidation in LAC also requires a clear assessment of public expenditures, which have grown significantly during the past two decades (Figure 32). The end of the commodities boom-compounded with the effect of the pandemic that will send 80 million people into poverty in the region- will impose the need to rethink some expenditure areas, forcing countries to do more with less. Fiscal consolidation must be reconciled with the need for increased social protection. Expenditure efficiency will prove to be a crucial reform agenda for the future. In this area, better targeting of social expenditureswhich currently do little to reduce inequality (5 percentage points in LAC's Gini coefficient, compared to 18 percentage points in advanced economies, Figure 33) is critical. The reform of pension systems, that in many countries are quite regressive, are also central to these efforts.
Figure 32. LA5: Primary Government Expenditures (Percent of GDP)

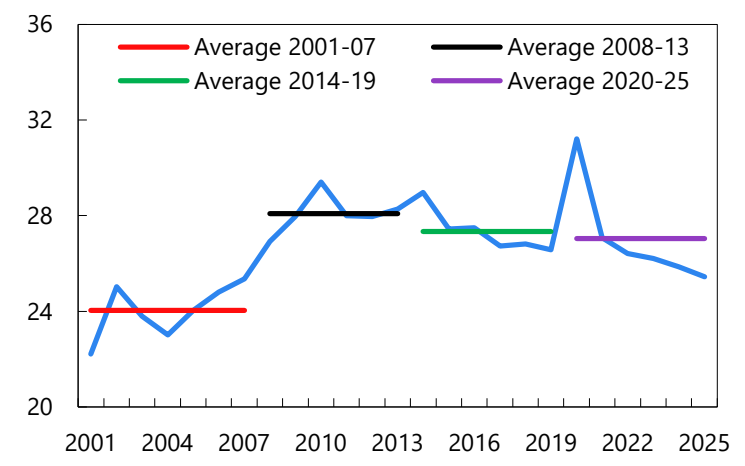

Sources: IMF, World Economic Outlook database; and IMF staff calculations. Note: Fiscal year US dollar nominal GDP-weighted average. LA5 = Brazil, Chile, Colombia, Mexico, Peru. 
However, across the board expenditure adjustments are not likely to work. On the one hand, cuts in certain areas can erase social achievements and could further deepen social tensions. On the other, public investment is needed to increase potential output, which is likely to have been reduced as a result of the pandemic. What this means is that the fiscal challenges are formidable. The region is at a crossroads: It needs to adjust to assure fiscal sustainability, but the wrong type of adjustment will send it in a downward spiral.

This makes the case for the rationalization of spending in the region. The key to intelligent spending is to engage in a conversation about expenditure composition, reversing the preference for expenditure programs that generate electoral support, rather than a significant effect either on growth-enhancing public investments or on poverty reduction. All of this begins with a better evaluation (and oversight) of public spending. The bias in the allocation of expenditures in favor of the old, relative to the young, also needs to be corrected.

The use of big-data systems could prove a critical step in improving spending efficiency. Integrating data between public and private entities to exchange and standardize information, coordinate policies, track how the resources are allocated, and enhance the targeting of social programs. Data integration will bring more transparency, lower costs of formality and more oversight to avoid tax evasion. ${ }^{13}$

\section{Institutional Fiscal Frameworks}

Revamping fiscal frameworks can help LAC countries push the boundaries of fiscal space, so as to be able to avoid an early withdrawal of fiscal stimulus, as discussed in previous sections. In the near term, the formal adoption of fiscal anchors, the leverage on explicit multi-year budget plans, the introduction or enhancement of fiscal councils to monitor and guide the process, and the improvement of communication strategies will improve efficiency and reduce fiscal risk, thus increasing market credibility, lowering interest rates, and widening much needed fiscal space. As in 2020 several LAC countries have suspended their fiscal rule, the resumption of the operation of these rules offers the perfect opportunity to upgrade these rules and complement them-where needed-with adequate supporting institutions (such as fiscal councils) and multiyear budgeting, thus improving the ability of fiscal frameworks to anchor medium term debt, harness expectations, recover deviations from targets, and secure adequate supervision. Once the crisis is over, such efforts should be followed by a more strategic and deeper overhaul of the fiscal frameworks, promoting the country ability to forestall future crisis.

${ }^{13 S e e ~ h t t p s: / / b l o g s . i a d b . o r g / g e s t i o n-f i s c a l / e s / m e j o r e s-p r a c t i c a s-s i s t e m a-i n t e l i g e n t e-d e-d a t o s-p a r a-l o s-g o b i e r n o s / . ~}$ 


\section{LAC Fiscal Frameworks helped during COVID-19, but need revamping}

A large number of LAC countries entered the pandemic crisis with the support of modern fiscal frameworks (Figure 34). Indeed, LAC countries were first movers in the adoption of fiscal rules, particularly when compared to other EMs. (see Annex 2 for a description of the types of fiscal rules adopted by LAC countries). ${ }^{14}$

However, fiscal frameworks in LAC countries are quite weak in terms of enforcement and effectiveness, despite improvements over the past few decades. Notably, fiscal councils remain very scant in LAC, present in only 20 percent of countries with fiscal rules in 2015 (see Figure 35). Escape clauses are more prevalent than fiscal councils, but still present in only less than half of the countries with a rule. Moreover, a formal enforcement of the rule remains a relative weakness of LAC countries.

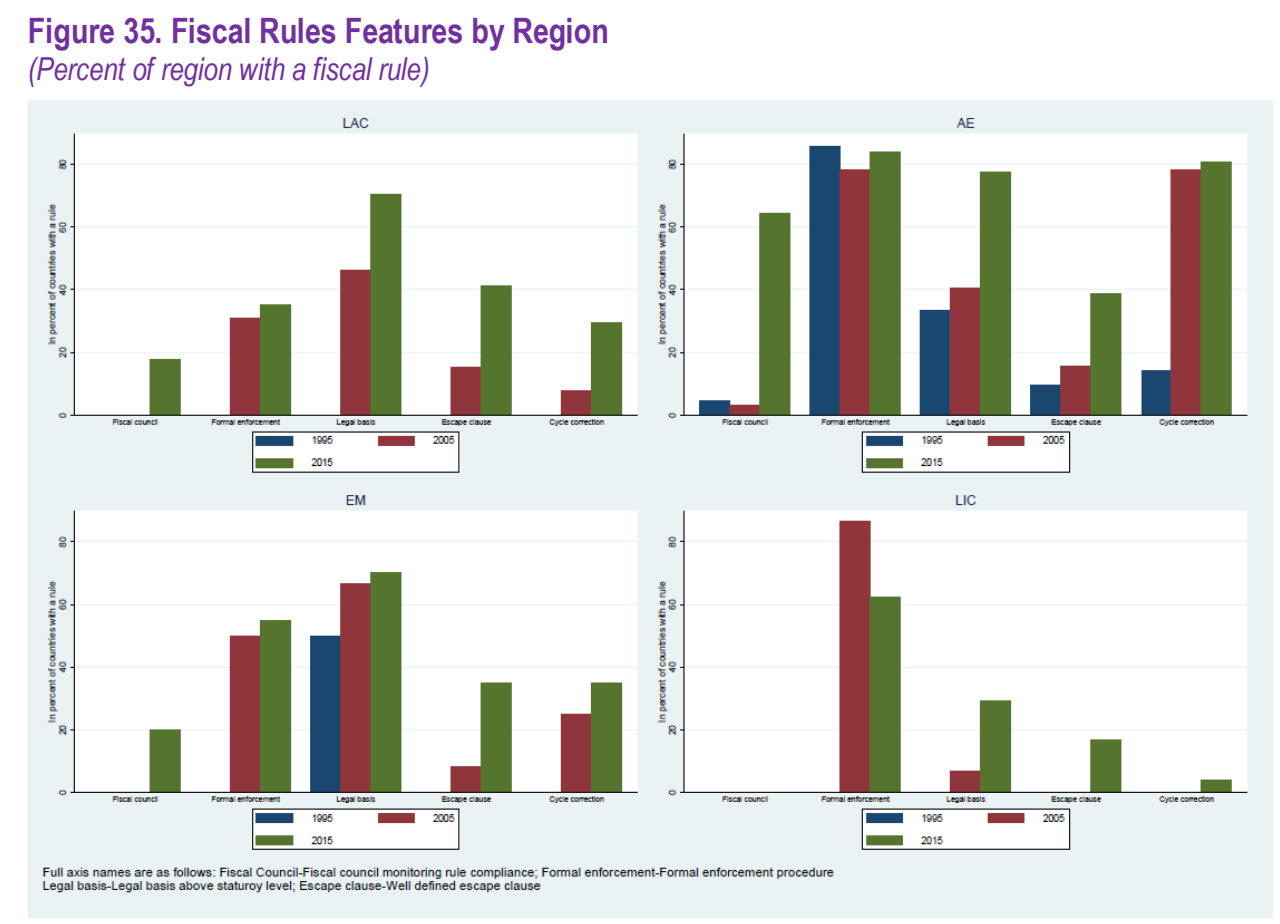

Sources: National authorities; and authors' calculations.
Figure 34. Countries with Fiscal Rule by Region (Percent of region)

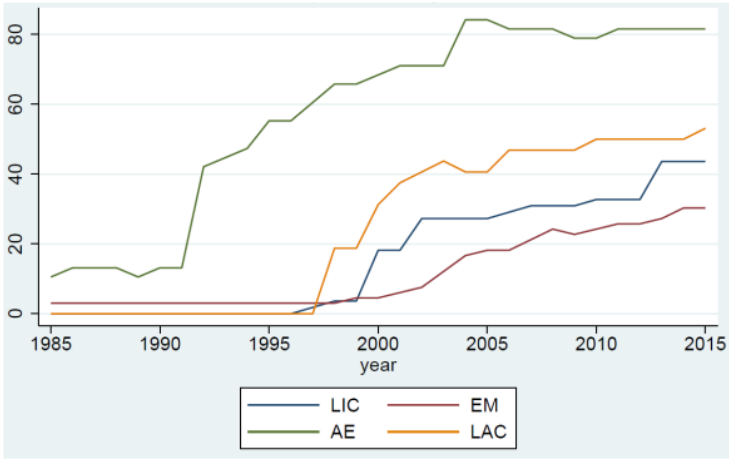

Sources: National authorities; and authors' calculations.

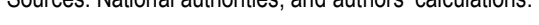

Indeed, Celasun et al (2015) point to the need to revamp LAC fiscal frameworks, in light of the deterioration of public finances since the GFC. Generally, fiscal rules have been found to be associated with a lower level of debt, fiscal deficit, and public expenditure (Debrun 2008, and IMF 2009, Ardanaz et al. 2020), and higher fiscal discipline (Eyraud et al 2018, IMF 2009). And indeed such rules helped LAC countries manage public finances while running countercyclical fiscal policy in essential times such as the Global Financial Crisis (GFC). However, fiscal institutions have not been adequate in stemming the persistent increase in LAC debt

${ }^{14}$ For an overview of the performance of fiscal rules in Latin America, as well as policy suggestions, see for example, Barreix and Corrales, 2019 IADB, and Celasun et al, 2015 IMF Staff Discussion Note. 
to GDP ratios since the GFC, exacerbated by the decline in commodity prices since mid-2010s, as the countercyclical fiscal policies during the GFC were not followed by a restoration of fiscal buffers. The authors highlight some pitfalls in the fiscal rules as part of the culprit: poorly designed escape clauses, limited symmetry in the response to expansion and downturns, associated limited ability to contain procyclicality, lack of multi-year horizon for fiscal policy, and - quite importantly — the need to rebuild adequate buffers, which should become an integral part of the fiscal rule itself. This implied that LAC countries entered the pandemic crisis with much higher debt ratios and weaker primary balances that when they entered the GFC.

In 2020, the majority of LAC countries with fiscal rules used some form of flexibility embedded in the rule in order to cope with rapidly increasing fiscal spending needs and declining government income (Figure 36). In about half of the cases, this was achieved via an escape clause, witnessing their importance in offering prompt flexibility. About one fifth of the countries (CHL and COL) adopted the cyclical relaxation embedded in their rule (related to both the output and commodity cycles). In a few cases the fiscal target was revised, while in the rest the rule was temporarily suspended.

The temporary suspension of the rule and the application of escape clauses has so far been announced for a limited time. Most countries that suspended the rule (COL, PRY, and PER), and some of those that invoked the escape clause (HND), did so Figure 36. Policy Relaxations Relative to Fiscal Rules, 2020 (Percent of GDP)

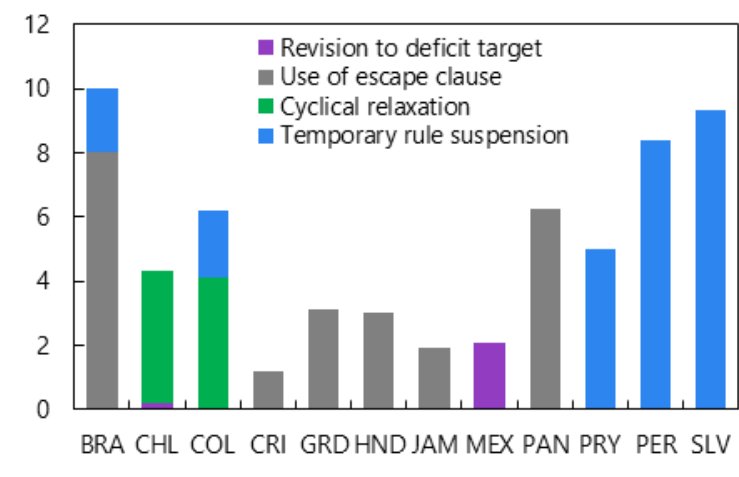

Sources: IMF, October 2020 Regional Economic Outlook: Western Hemisphere; country reports; national authorities; and IMF staff calculations. until 2021, planning to return to the guidance of the rule in 2022.

However, existing fiscal frameworks offer limited guidance on how countries will return to their targets, the extent to which the sizable swelling of fiscal deficits will be reabsorbed, and how to navigate when deviations from the rules are in place-as evidenced by the aforementioned experience after the GFC. Such limited guidance hinders the credibility of authorities' commitments to quick return to their fiscal targets.

On the positive side, fiscal rules may have helped contain the increase in spreads during the COVID-19 episode for LAC countries. Quite generally, Afonso and Tovar Jalles (2019) find that fiscal rules tend to be associated with lower spreads, as well as a lower response of spreads to recessions. ${ }^{15}$ More precisely, the conditional correlation charts (Figure 37) offers some suggesting evidence that in LAC countries the change in spread since COVID-19 (from end-February to end-September 2020) was not only adversely affected by the increase in the 2025 forecast for debt to GDP (comparing WEO projection in October 2020 versus October 2019) — as expected—but was also lower in countries with a fiscal rule. ${ }^{16}$

\footnotetext{
${ }^{15}$ Heinemann, Osterloh, and Kalb (2013) find that such an effect of fiscal rules tends to be larger for countries with particularly poor stability culture in the past, which could suggest a sizable potential for LAC countries adopting or strengthening their rules.

${ }^{16}$ The conditional correlation charts are based on a regression of the change in spread on the change in debt to GDP ratio and the presence of a fiscal rule. The coefficients are significant and imply that increase in debt by 10 percentage points of GDP is associated with an increase in spread by about 110bps, while the presence of a fiscal rule is associated with lower spreads rise by about 220 bps.
} 
Figure 37. Conditional Correlation of EMBI on Debt or Rule of Law
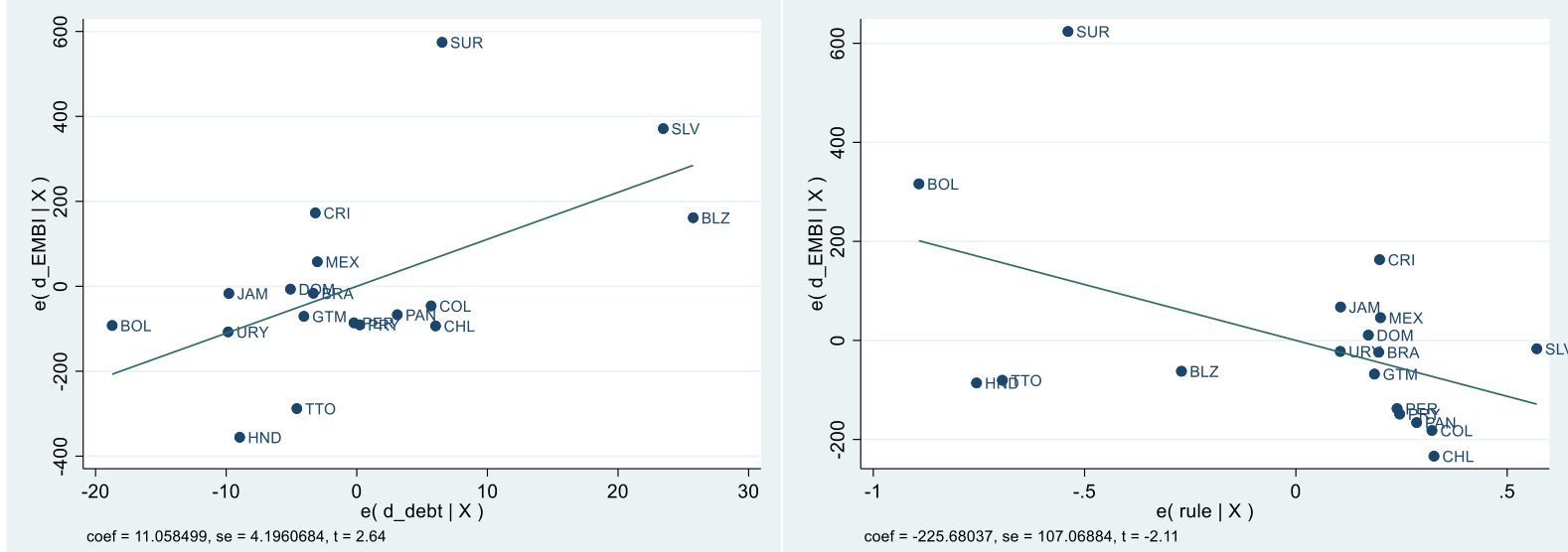

Source: Authors' calculations, based on a regression with both variables.

In the near term, LAC fiscal frameworks need an urgent upgrade to support fiscal efforts during the recovery

Going forward, the strengthening of fiscal frameworks should complement and support the two-stage policy agenda discussed above. Overall, the institutional fiscal frameworks available to LAC countries have generally offered adequate flexibility to allow fiscal policy to respond to the pandemic, but have often failed to ensure an adequate fiscal adjustment after deviations from targets, which is a risk that needs to be urgently addressed if LAC authorities want to leverage on existing fiscal space to continue supporting the recovery from the pandemic without endangering fiscal sustainability. More generally, a refinement of the institutional framework would be appropriate to enhance at the same time both the medium-term commitments and the short-term flexibility, by upgrading fiscal anchoring, multi-annual projections and budgetary plans, adjustment mechanisms, supervision, enforcement and communication, which would enhance discipline and credibility. While a substantial overhaul of the fiscal frameworks is not feasible (nor desirable) in the short term - as the attention of the authorities would be mainly devoted to securing an effective and inclusive transition out of the pandemic crisis - the need for same urgent enhancements to these frameworks calls for a two-stage approach in line with the rest of the paper.

During the first stage, the most urgent step would be to communicate a credible fiscal strategy, via temporary legislation which would clearly define a credible fiscal path towards debt stability over the medium term, with adequate checks and balances. This strategy towards debt stability should be supported by an adequate commitment, and well communicated to anchor expectations on the future evolution of indebtedness at a time where more stimulus could be necessary in the short-term to cope with the ongoing pandemic and other possible shocks.

The fiscal strategy should clarify an overall debt path and a multi-annual budgetary plan with a clear path for operational targets such as the primary balance, and how such path will place debt on a downward trend over the medium term, while ensuring sufficient space for capital expenditure necessary for medium-term development plans. The strategy should envisage both the timing and conditions under which the ongoing fiscal stimulus should be withdrawn, so that fiscal consolidation plans would be state-contingent on the developments of key economic indicators, and more generally under what conditions the medium-term debt target path should be revisited. Indeed, large changes in key indicators—such as employment, growth, bankruptcies, defaults, and distributional issues — could help inform a (formal or informal) "escape clause" in case additional shocks arise or the effect of the pandemic is deeper than anticipated (deviations could be assessed on the basis of multiple standard deviation changes from historical benchmarks). This would be particularly relevant to enhance credibility and anchor expectations, especially in the face of adverse shocks.

Credibility and enforcement can leverage on a strong role for independent fiscal councils. Fiscal councils could be assigned with the task of monitoring the ongoing and expected evolution of fiscal aggregates and 
check their consistency with the medium-term debt path. They could present frequent (such as quarterly) assessments and projections, which would strengthen discipline and credibility. Their involvement in case of deviations from plans would depend on the institutional setup of the country, but where possible a formal approval from the fiscal council (for example on the basis of a qualified majority) could be envisaged.

\section{In the medium term, a comprehensive overhaul of the fiscal framework. would be crucial to better prepare countries for future crises}

Once the urgent challenges posed by the pandemic are addressed (i.e., in stage 2), countries should focus on a broad overhaul of fiscal frameworks to enhance anchoring, flexibility, supervision, enforcement, and communication, which would strengthen effectiveness, discipline, and credibility. At this stage it would be essential to focus on rebuilding buffers in a well-anchored and credible system, but also to ensure that the system builds-in adequate flexibility to "escape" from the rule when appropriate, and that an adequate adjustment mechanisms can guide the system back to a long term anchor. This will require also a stronger supervisory role of fiscal councils to promote enforcement and discipline, and an improved communication strategy to adequately guide expectations and leverage on the discipline offered by the fiscal frameworks.

Ensuring the presence of an explicit medium-term fiscal anchor is a fundamental step to strengthen the framework and enhance credibility (accompanied of course by adequate and well-designed operational rules, monitoring, and enforcement systems). This would not only help secure adequate buffers, but also enhance robustness of the rule to significant structural changes in the economy (such as a decline in productivity or commodity prices). The anchoring system should be grounded in the main goals of the fiscal rules (such as intergenerational equity, fair use of public natural resources when present, flexible adjustment to shocks, and debt sustainability). The precise fiscal anchor should be spelled out explicitly, encompassing to the extent possible a broadly adequate definition of public sector assets and liabilities (such as the net debt position of the non-financial public sector, which would contain perverse incentives to finance expenditure via belowthe-line measures, public assets, or public companies). A buffer could be achieved by setting a debt ceiling below the thresholds that the authorities do not deem appropriate to surpass (for market access or sustainability concerns), and should be evaluated on the basis of the macroeconomic volatility of the country and the possible appropriate temporary fiscal response in case of shocks. Debt buffers would help avoid fiscal pro-cyclicality during an adverse shock, by preserving ex-ante adequate fiscal space to cushion the shock without reaching the ceiling. Of course, this implies the need to replenish buffers after an adverse shock. And in case of repeated or persistent negative shocks, it may be necessary to revisit the level of the ceiling and/or buffer (if feasible) or the fiscal strategy. More generally, the fiscal rule law should offer guidance as to how to regularly update these ceilings or targets depending on global and domestic circumstances. At the same time, countries could reassess the effectiveness of their operational targets — often related to flow measures such as cyclically adjusted fiscal balance — and the possible value offered by expenditure targets. ${ }^{17}$ Note that it is not ideal to adopt flow measures as final targets without a debt stock anchor, as this would make it easy for debt to ratchet up whenever flow targets are missed due to adverse shocks.

A well-designed system requires also adequate flexibility to deal with shocks and preserve high-quality spending, via formal escape clauses. For those countries that do not currently envisage them, such clauses could be introduced envisaging a well-defined set of trigger events, limiting the time horizon of the deviation from the rule, and spelling-out an adjustment mechanism that would bring back the public finances towards the targets and medium-term anchors offsetting the accumulated deviations (see for example Gbohoui and Medas, 2020). Moreover, it is important to avoid that a fiscal adjustment necessary to comply with the rule would myopically end up in an undesirable compression of highly-productive spending like investment, which is often employed as the residual budgetary adjustment margin towards year-end (for example by adopting special provisions or separate borrowing arrangements for high-productive investment, or capping current

\footnotetext{
${ }^{17}$ Over the past decade, many advanced economies have progressively moved or complemented their fiscal rules with expenditure rules, whereby public expenditure is kept below a well-calibrated stable path of expenditure consistent with medium term goals. Expenditure rules have been praised as simple, less affected by arbitrary and complex parametrization, and more stable. Indeed, several LAC countries_notably Mexico and Peru—have complemented their framework with such a rule.
} 
spending, though these adjustments may give raise to definitional issues and perverse incentives). Finally, strengthening automatic stabilizers would also enhance the flexibility of the system.

The overall framework requires a strong enforcement mechanism, such as via independent fiscal supervisory agencies — notably fiscal councils—which would strengthen credibility, particularly by checking and validating the accuracy of the authorities' announcement about fiscal plans, and the consistency of such plans with operational targets and medium-term anchors, thus ensuring compliance towards reaching medium-term anchors especially when deviations from the rule are warranted (for example via escape clauses). The use of fiscal councils is still limited in LAC and EM world. The extent and precise design of their role may need to differ from country to country depending on the overall institutional characteristics. However, it would be generally appropriate to envisage that when the government presents the fiscal plan to Congress, the fiscal council would present an independent evaluation of the consistency of such a plan with the existing fiscal targets and anchors embedded in the fiscal rule. The public role of fiscal council may be particularly effective in promoting compliance via reputational costs (often seen as more effective than penalties).

The role of independent fiscal councils would be particularly important at times when temporary deviation from the rule is warranted, in order to strike the right balance between ensuring adequate flexibility and restoring discipline, as it is precisely under these circumstances (such as the current pandemic) that an independent agency needs to guide the process of returning towards the fiscal targets and anchors in the medium term. Indeed, it could be very difficult_ or even inappropriate_-for a fiscal rule to prescribe a strict enforcement mechanism that apply to any unpredictable exceptional circumstance. Independence (and adequate funding) is paramount and could be enhanced by setting the duration of nomination terms differently from those of the executive powers and different across council members, and by nominating council members as full-time employee selected among public figures of undoubtful reputation. By way of a comparison, establishing independent fiscal councils with strong supervisory roles could enhance the effectiveness and credibility of fiscal rules, similarly to how the establishment of independent central banks in the past decades has enhanced the quality of monetary institutions and policy making across the globe over the past few decades.

An effective communication strategy would allow a well-designed system to reap the credibility benefits it deserves. First of all, the rule should be formulated and communicated in a simple way. Fiscal medium-term projections should be published quarterly, clarifying how targets would be met within the anchoring framework, and eliciting a healthy public debate including with the fiscal council. In distressed times, the escape clause should be formally invoked, offering clear explanations for the rationale as well as a clear plan for the necessary medium-term fiscal adjustment and its consistency with the operational targets and the anchoring system.

Going forward, the envisaged two-step policy approach to complementing and revisiting fiscal frameworks would allow fiscal policy to credibly and effectively promote the recovery while preserving medium term stability. Indeed, there is an opportunity to quickly "boost" the fiscal frameworks to ensure that the needed short-term fiscal flexibility is not at the expense of medium-term debt sustainability, while waiting for the appropriate moment for a comprehensive overhaul of fiscal frameworks which would offer a long term legacy preparing fiscal policy for dealing adequately with future economic fluctuations and crises.

\section{Conclusions}

The fiscal policy response to the COVID-19 shock in most LAC countries was much larger than the one during the GFC, despite worse initial conditions, suggesting fiscal space was not as tight as initially estimated. To avoid an early and excessive withdrawal of support in 2021 and 2022, we have argued it is feasible and desirable, to embark on a more gradual consolidation path than currently envisaged by several countries in the region, under the assumption that this is done together with stronger commitments and institutional changes that ensure debt is put on a downward trajectory once the pandemic is under control. This strategy is not without risks, but is facilitated by the low-for-longer level of interest rates, and debt management strategies that preserve low and stable interest payments. Avoiding a large fiscal drag in 2021 with continued support, albeit at lower levels than in 2020, would be 
an insurance policy for the recovery, especially now that there is less uncertainty about possible treatments and vaccines to control the pandemic. And it would lead to better economic and social outcomes.

On key reason why fiscal space was larger than anticipated in 2020 is associated with the secular decline in interest rates, that has compensated to a large extent for the higher debt. At the center of this paper's argument is our conviction that fiscal space is not set in stone and it is endogenous to the medium-term targets and commitments undertaken by governments and congresses that would ensure a gradual consolidation once the pandemic is under control. To achieve this, the fiscal targets that are decided should be accompanied with measures that increase public sector net revenues once the economy and employment levels are clearly on the mend and close to potential. In the near term, countries could better target some of the emergency measures adopted in 2020, focus on dealing with the legacy effects of the pandemic on poverty and inequality as well as on enhancing social protection, improving revenues and reorienting expenditures. Moreover, revisions to fiscal responsibility frameworks should be helpful to anchor fiscal sustainability, as well as to improve their effectiveness and flexibility. Also, the formal adoption of fiscal anchors, introduction or strengthening of fiscal councils, and enhancement of communication strategies will improve efficiency and reduce fiscal risk, thus increasing credibility, lowering interest rates, and widening much needed fiscal space.

This agenda is definitively challenging and risky but if it is neglected the continuation of low growth, social discontent, and political polarization will drive Latin America towards a very dangerous path of institutional and economic decay. Catalyzing such changes would require a broad social consensus and political cohesion around several crucial dimensions of public finances: a fiscal pact. In a first stage, the abovementioned policy actions would allow for a faster closure of output and poverty gaps, while ensuring the preservation of access to market funding - or eventually, contingent or actual IFI's support. The second stage would start with a social dialogue on how to broaden the social safety net and how to finance it, to assess society's preferences regarding the tax and expenditure implications behind these very consequential tradeoffs. This public dialogue should serve as a basis into the legislative process that should take place in the next couple of years to revise pensions, health, and educational systems as well as reforming tax frameworks to support it. 


\section{References}

Arze del Granado, Javier, Kimberly Beaton, and Aliona Cebotari, (2018), "Designing a Fairer Form of Fiscal Consolidation in Latin America", Dialogo a Fondo, IMF Blog

Aziz, J. et al, 2020, “This Time is Different”, Economic Research Note, JP Morgan

Afonso António, João Tovar Jalles, 2019, "Fiscal Rules and Government Financing Costs," vol 40.

Hannan, A. S., K. Honjo, and M. Raissi, 2020, "Mexico Needs a Fiscal Twist: Response to COVID-19 and Beyond", IMF WP/20/215

Ardanaz, Martín, Eduardo Cavallo, Alejandro Izquierdo, Jorge Puig, 2020, “Growth Friendly Fiscal Rules: Safeguarding Public Investment from Budget Cuts through Fiscal Rule Design" IADB, mimeo

Barreix and Corrales, 2019 "Reglas fiscales resilientes en América Latina”, IADB, mimeo

Celasun Oya, Francesco Grigoli, Keiko Honjo, Javier Kapsoli, Alexander Klemm, Bogdan Lissovolik, Jan Luksic, Marialuz Moreno-Badia, Joana Pereira, Marcos Poplawski-Ribeiro, Baoping Shang, and Yulia Ustyugova, 2015, "Fiscal Policy in Latin America, Lessons and Policies from the Global Financial Crisis", IMF Staff Discussion Note

Debrun, X., L. Moulin, A. Turrini, J. Ayuso-i-Casals and M. S. Kumar. 2008. "Tied to the Mast? National Fiscal Rules in the European Union”. Economic Policy, 23(54): 298-362.

Economist Intelligence Unit, 2020, “Peru’s private sector credit growth reaches new highs”, Peru Financial Services, November.

Eyraud, L., M. X. Debrun, A. Hodge, V. D. Lledo and M. C. A. Pattillo. 2018. "Second-Generation Fiscal Rules: Balancing Simplicity, Flexibility, and Enforceability”. IMF Staff Discussion Notes

Furman, Jason and Lawrence Summers, 2020, “A Reconsideration of Fiscal Policy in the Era of Low Interest Rates", mimeo.

Gbohoui William and Paulo Medas, 2020, "Fiscal rules, Escape Clauses, and Large Shocks", IMF Fiscal Affairs Department, Special Series on Fiscal Policies to Respond to Covid

Heinemann Friedrich, Steffen Osterloh, and Alexander Kalb, 2013, “Sovereign Risk Premia: The Link Between Fiscal Rules and Stability Culture”, Discussion Paper No. 13-016

IMF-WHD Regional Outlook, 2020, "Pandemic Persistence Clouds the Recovery”, October, Chapter 1

IMF-WHD Regional Outlook, 2020, "Fiscal Policy in times of the Pandemic", October, Chapter 4

IMF, 2009. Fiscal Rules: “Anchoring Expectations for Sustainable Public Finances”. Fiscal Affairs Department Discussion notes

IMF, 2015. "Fiscal Policy in Latin America: Lessons and Legacies of the Global Financial Crisis," Staff Discussion Note 15/06, Washington, DC.

Izquierdo, A, C. Pessino and G. Vuletin, 2018, "Better Spending for Better Lives", IADB, DIA Report

Felipe Larraín, Luca Antonio Ricci, Klaus Schmidt-Hebbel, Hermann González, Metodij Hadzi-Vaskov, and Andrés Pérez (2019), "Enhancing Chile's Fiscal Framework: Lessons from Domestic and International Experience", IMF.

Mauro, Paolo and Jing Zhou, “(r-g)<0: Can We Sleep More Soundly?”, IMF WP/20/52.

Sturzenegger, Federico, 2020, “Do We Need to Rethink Debt Policy in Latam?”, UNDP LAC C19 PDS No. 23. 


\section{Annex 1: Gradual Consolidation, Scarring and Debt Risks}

Section IV present two sets alternative scenarios that build on baseline scenarios for the LAC countries. The first set assumes a continuation of support, at lower levels than 2020 (3\% GDP in 2021 and 2\% GDP in 2022), and the removal of such support with different degrees of gradualism. The second set aims to show that a somewhat more modest level of continued support could even "pay itself" over time by avoiding the scarring effects on human and physical capital of a sharp consolidation in 2021-22.

The assumptions and results from the first set of scenarios until 2030 is summarized in the next table

Annex Table 1.1. Assumptions and Summary of Results

\begin{tabular}{|c|c|c|c|c|c|c|c|c|c|c|c|}
\hline & \multicolumn{11}{|c|}{ Projections } \\
\hline & 2020 & 2021 & 2022 & 2023 & 2024 & 2025 & 2026 & 2027 & 2028 & 2029 & 2030 \\
\hline \multicolumn{12}{|l|}{ Scenario 1 Assumptions } \\
\hline Nominal growth & & 3.0 & 2.0 & -2.0 & -3.0 & & & & & & \\
\hline Primary balance & & -3.0 & -2.0 & 2.0 & 3.0 & & & & & & \\
\hline Effective interest rate & & 0.50 & 0.75 & 0.50 & 0.25 & & & & & & \\
\hline \multicolumn{12}{|l|}{ Scenario 1 Results } \\
\hline Gross debt & 71.5 & 73.0 & 74.3 & 74.3 & 73.8 & 73.5 & 73.2 & 72.9 & 72.6 & 72.3 & 72.0 \\
\hline Primary balance & -6.2 & -4.9 & -2.9 & 1.5 & 2.9 & 0.2 & 0.2 & 0.2 & 0.2 & 0.2 & 0.2 \\
\hline $\mathrm{r}$ - g (percentage points) & 10.03 & -5.15 & -2.41 & 2.08 & 3.23 & -0.09 & -0.09 & -0.09 & -0.09 & -0.09 & -0.09 \\
\hline \multicolumn{12}{|l|}{ Scenario 2 Assumptions } \\
\hline Nominal growth & & 3.0 & 2.0 & -1.0 & -1.0 & -1.0 & -1.0 & -1.0 & & & \\
\hline Primary balance & & -3.0 & -2.0 & 1.0 & 1.0 & 1.0 & 1.0 & 1.0 & & & \\
\hline Effective interest rate & & 0.50 & 0.75 & 0.60 & 0.30 & 0.15 & & & & & \\
\hline \multicolumn{12}{|l|}{ Scenario 2 Results } \\
\hline Gross debt & 71.5 & 73.0 & 74.3 & 74.7 & 74.7 & 74.2 & 73.6 & 73.0 & 72.7 & 72.4 & 72.2 \\
\hline Primary balance & -6.2 & -4.9 & -2.9 & 0.5 & 0.9 & 1.2 & 1.2 & 1.2 & 0.2 & 0.2 & 0.2 \\
\hline$r$ - g (percentage points) & 10.03 & -5.15 & -2.41 & 1.18 & 1.28 & 1.06 & 0.91 & 0.91 & -0.09 & -0.09 & -0.09 \\
\hline \multicolumn{12}{|l|}{ Scenario 3 Assumptions } \\
\hline Nominal growth & & 3.0 & 2.0 & -1.0 & -0.5 & -0.5 & -0.5 & -0.5 & -0.5 & -0.5 & -1.0 \\
\hline Primary balance & & -3.0 & -2.0 & 1.0 & 0.5 & 0.5 & 0.5 & 0.5 & 0.5 & 0.5 & 1.0 \\
\hline Effective interest rate & & 0.50 & 0.75 & 0.60 & 0.50 & 0.40 & 0.30 & 0.20 & 0.10 & & \\
\hline \multicolumn{12}{|l|}{ Scenario 3 Results } \\
\hline Gross debt & 71.5 & 73.0 & 74.3 & 74.7 & 75.0 & 74.8 & 74.6 & 74.3 & 73.9 & 73.5 & 72.9 \\
\hline Primary balance & -6.2 & -4.9 & -2.9 & 0.5 & 0.4 & 0.7 & 0.7 & 0.7 & 0.7 & 0.7 & 1.2 \\
\hline $\mathrm{r}$ - g (percentage points) & 10.03 & -5.15 & -2.41 & 1.18 & 0.98 & 0.81 & 0.71 & 0.61 & 0.51 & 0.41 & 0.91 \\
\hline
\end{tabular}

Sources: IMF, World Economic Outlook database; and IMF staff calculations.

The second set of scenarios incorporate a more (less) gradual consolidation in 2021 and 2022, with conservative assumptions about scarring and projections until 2030

Scenario A: add -2\% GDP to primary balance in 2021 and -1\% GDP in 2022, two multipliers to get growth $(1,4 / 3)$, and add $50 \mathrm{bps}$ to interest rate; the avoidance of scarring and additional measures allow for $0.3 \%$ of above baseline growth in the years to 2030 .

Scenario B: add $+2 \%$ GDP to pb, two multipliers to get growth $(1,4 / 3)$, and reduce 50 bps to interest rate.

Results for this second set of scenarios are shown in Figure 24 of the text.

Finally, we conduct a series of Stress Tests around the baseline path of the debt-to-GDP ratio. The Fan Chart around the baseline is produced with 6000 draws from a multivariate normal distribution of the four variables, using ICD's Debt Dynamics Tool. The shocks are one- and three-standard deviation shocks derived from the historical distribution of the regional series. The underlying assumptions are detailed in the table below: 
Annex Table 1.2. Stress Tests Assumptions and Results

\begin{tabular}{lcc}
\hline & Standard Deviation & Baseline Value (2021) \\
\hline Interest rate & 3.4 & 5.7 \\
Real GDP growth & 2.6 & 2.6 \\
Primary balance & -1.9 & -1.9 \\
& & \\
\hline & Percentage Change & New Value \\
Stress Test 1 & & \\
Interest rate & 3.4 & 9.1 \\
Real GDP growth & -2.6 & 0 \\
Primary balance & -2.0 & -4.0 \\
& & \\
Stress Test 2 & 10.2 & 15.9 \\
Interest rate & -7.8 & -5.3 \\
Real GDP growth & -6.0 & -7.9 \\
Primary balance & & \\
\hline
\end{tabular}

Sources: IMF, World Economic Outlook database; and IMF staff calculations.

Annex Table 1.3. Underlying Assumptions: One Standard Deviation Shock (Percent)

\begin{tabular}{|c|c|c|c|c|c|c|}
\hline & 2021 & 2022 & 2023 & 2024 & 2025 & 2026 \\
\hline \multicolumn{7}{|l|}{ Baseline } \\
\hline Real GDP growth & 2.6 & 4.7 & 3.0 & 2.0 & 1.7 & 1.7 \\
\hline Inflation & 5.7 & 3.9 & 3.5 & 3.2 & 3.2 & 3.2 \\
\hline Primary balance & -1.9 & -0.9 & -0.5 & -0.1 & 0.2 & 0.2 \\
\hline \multirow[t]{2}{*}{ Effective interest rate } & 5.7 & 5.6 & 5.8 & 5.8 & 5.9 & 5.9 \\
\hline & 0.0 & 0.0 & 0.0 & 0.0 & 0.0 & 0.0 \\
\hline Real Interest Rate Shock & 0.0 & 0.0 & 0.0 & 0.0 & 0.0 & 0.0 \\
\hline Real GDP growth & 2.6 & 4.7 & 3.0 & 2.0 & 1.7 & 1.7 \\
\hline Inflation & 5.7 & 3.9 & 3.5 & 3.2 & 3.2 & 3.2 \\
\hline Primary balance & -1.9 & -0.9 & -0.5 & -0.1 & 0.2 & 0.2 \\
\hline Effective interest rate & 9.1 & 5.6 & 5.8 & 5.8 & 5.9 & 5.9 \\
\hline \multicolumn{7}{|l|}{ Primary Balance Shock } \\
\hline Real GDP growth & 2.6 & 4.7 & 3.0 & 2.0 & 1.7 & 1.7 \\
\hline Inflation & 5.7 & 3.9 & 3.5 & 3.2 & 3.2 & 3.2 \\
\hline Primary balance & -4.0 & -0.9 & -0.5 & -0.1 & 0.2 & 0.2 \\
\hline Effective interest rate & 5.7 & 5.6 & 5.8 & 5.8 & 5.9 & 5.9 \\
\hline \multicolumn{7}{|l|}{ Real GDP Growth Shock } \\
\hline Real GDP growth & 0.0 & 4.7 & 3.0 & 2.0 & 1.7 & 1.7 \\
\hline Inflation & 5.7 & 3.9 & 3.5 & 3.2 & 3.2 & 3.2 \\
\hline Primary balance & -1.9 & -0.9 & -0.5 & -0.1 & 0.2 & 0.2 \\
\hline Effective interest rate & 5.7 & 5.6 & 5.8 & 5.8 & 5.9 & 5.9 \\
\hline
\end{tabular}

Sources: IMF, World Economic Outlook database; and IMF staff calculations. 
Annex Table 1.4. Underlying Assumptions: Three Standard Deviation Shock (Percent)

\begin{tabular}{|c|c|c|c|c|c|c|}
\hline & 2021 & 2022 & 2023 & 2024 & 2025 & 2026 \\
\hline \multicolumn{7}{|l|}{ Baseline } \\
\hline Real GDP growth & 2.6 & 4.7 & 3.0 & 2.0 & 1.7 & 1.7 \\
\hline Inflation & 5.7 & 3.9 & 3.5 & 3.2 & 3.2 & 3.2 \\
\hline Primary balance & -1.9 & -0.9 & -0.5 & -0.1 & 0.2 & 0.2 \\
\hline Effective interest rate & 5.7 & 5.6 & 5.8 & 5.8 & 5.9 & 5.9 \\
\hline \multicolumn{7}{|c|}{ Real Interest Rate Shock } \\
\hline Real GDP growth & 2.6 & 4.7 & 3.0 & 2.0 & 1.7 & 1.7 \\
\hline Inflation & 5.7 & 3.9 & 3.5 & 3.2 & 3.2 & 3.2 \\
\hline Primary balance & -1.9 & -0.9 & -0.5 & -0.1 & 0.2 & 0.2 \\
\hline Effective interest rate & 15.9 & 5.6 & 5.8 & 5.8 & 5.9 & 5.9 \\
\hline \multicolumn{7}{|l|}{ Primary Balance Shock } \\
\hline Real GDP growth & 2.6 & 4.7 & 3.0 & 2.0 & 1.7 & 1.7 \\
\hline Inflation & 5.7 & 3.9 & 3.5 & 3.2 & 3.2 & 3.2 \\
\hline Primary balance & -7.9 & -0.9 & -0.5 & -0.1 & 0.2 & 0.2 \\
\hline Effective interest rate & 5.7 & 5.6 & 5.8 & 5.8 & 5.9 & 5.9 \\
\hline \multicolumn{7}{|c|}{ Real GDP Growth Shock } \\
\hline Real GDP growth & -5.3 & 4.7 & 3.0 & 2.0 & 1.7 & 1.7 \\
\hline Inflation & 5.7 & 3.9 & 3.5 & 3.2 & 3.2 & 3.2 \\
\hline Primary balance & -1.9 & -0.9 & -0.5 & -0.1 & 0.2 & 0.2 \\
\hline Effective interest rate & 5.7 & 5.6 & 5.8 & 5.8 & 5.9 & 5.9 \\
\hline
\end{tabular}

Sources: IMF, World Economic Outlook database; and IMF staff calculations. 


\section{Annex 2: Types of Fiscal Rules in LAC}

Debt rules became the most prevalent types of fiscal rules among LAC countries, surpassing budget rules in mid-2000s. During the initial phase of adoption of fiscal rule, most countries were following budget rules. However, ahead of the global financial crisis, the preference progressively shifted towards a preference for debt rules. Such behavioral pattern was common to the emerging and developing world. In AEs, in the aftermath of the 2008 global crisis, there was a sudden rise in expenditure rules, which were seen as more reliable and less subject to the choice of the definition of the budget and the associated complex calculations issues. The preference in LAC countries fell on debt rules, followed by deficit rules.

\section{LAC countries seem to rely less combinations of alternative types of rules, than both other EM and AE}

countries. Peru and Grenada are the two notable exceptions, relying simultaneously on a budget, debt and expenditure rule.

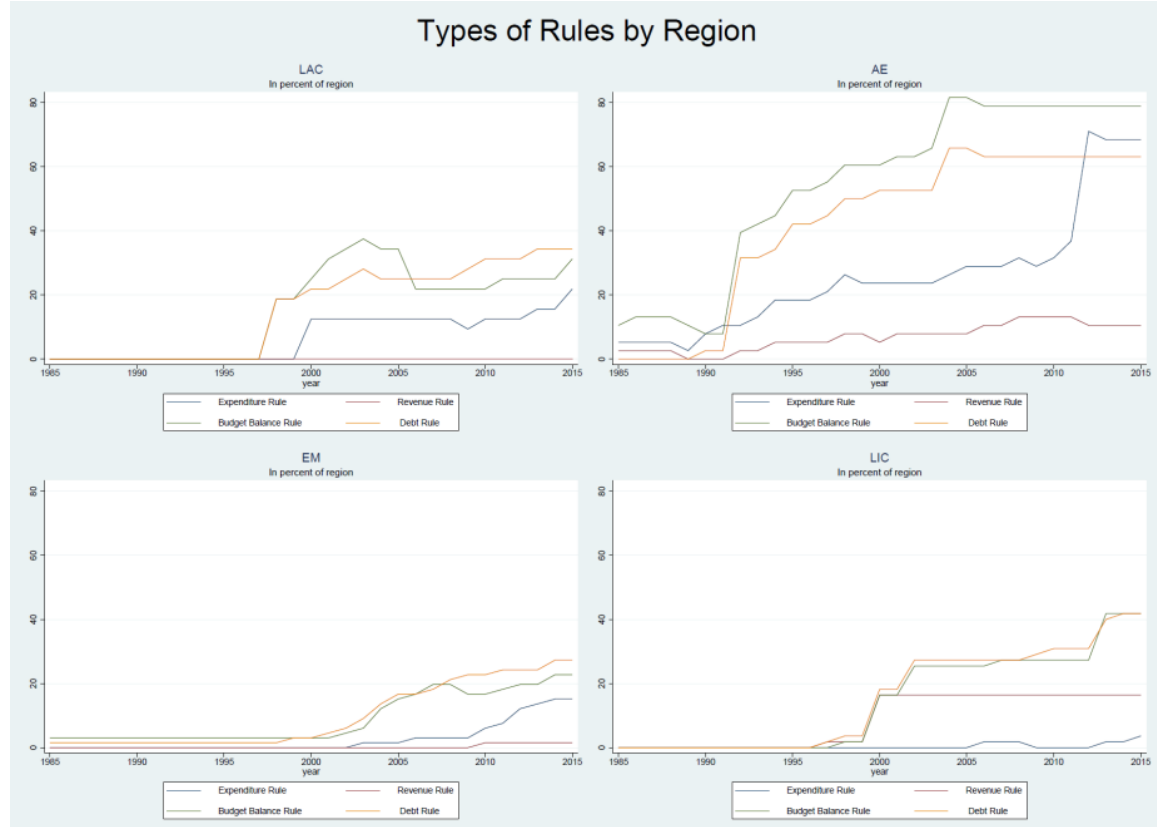

\section{Combination of Rules}

Venn Diagram: LAC

$\mathrm{N}=22$

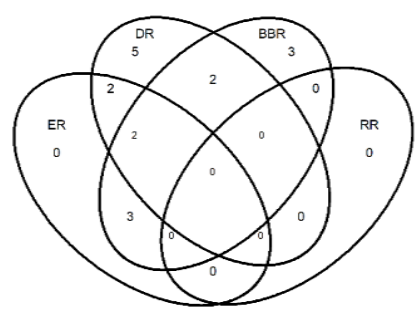

Venn Diagram: EM

$N=21$

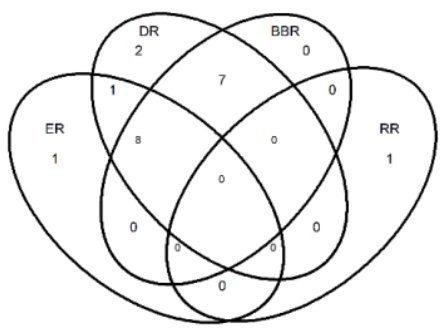

Venn Diagram: AE

$N=33$

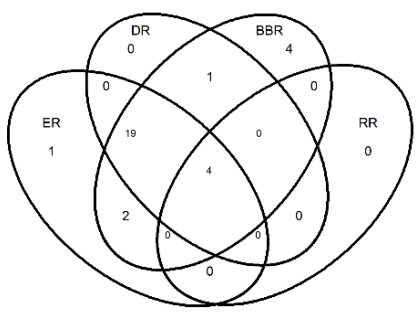

Venn Diagram: LIC

$\mathrm{N}=24$

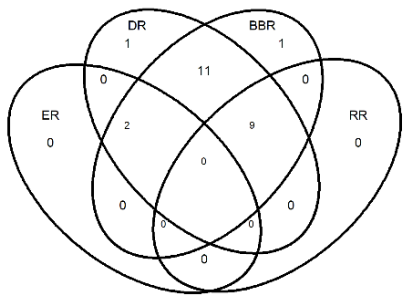

Source: IMF, Fiscal Affairs Department, Fiscal Rule Database. 